Linköping Studies in Science and Technology

Thesis No. 1638

LiU-TEK-LIC 2013:172

\title{
Entering renewable electricity production \\ - An actor perspective
}

\author{
Ingrid Mignon
}

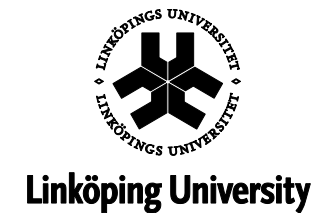

2014

Department of Management and Engineering

Linköping University

SE-581 83 Linköping

Sweden 
Cover art by Björn Hesselstrand

(C) Ingrid Mignon 2014

Linköping studies in science and technology, Thesis No. 1638

LiU-TEK-Lic 2013:72

ISBN: 978-91-7519-435-6

ISSN: 0280-7971

Printed by: LiU-Tryck, Linköping

Distributed by:

Linköping University

Department of Management and Engineering 


\section{Abstract}

Although energy transition is considered one of the main challenges of our time, little attention has traditionally been paid to the actors participating in this transition, such as the producers of renewable electricity. Previous energy policy literature and policymakers have assumed that these producers are incumbent actors of the current energy system, that is to say, large utilities producing both renewable and fossil-fueled electricity. In reality, new types of producers are entering the renewable electricity production market, without much (if any) previous experience in that industry.

This Licentiate thesis studies the new entrants of renewable electricity production in order to identify their motives, their responses to policies, and their ways of implementing their projects. This is conducted through the analysis of 37 cases of new entrants in Sweden. A theoretical background, a complete description of the methods, and an overall presentation of the findings are presented in the first part of the thesis, and in the second part of the thesis, four scientific papers studying the new entrants of renewable electricity production from complementary theoretical approaches are presented.

Results show that the new entrant group is heterogeneous in several ways. They have different motives, they are affected by different drivers and pressures, and they are faced with different challenges during their entry processes. Despite that, their share of investments represents the majority of those currently being made in renewable electricity production in Sweden.

Based on these results, policy implications are drawn and, in particular, the need for policy-makers and energy policy literature to acknowledge the particularities of the new entrants is highlighted.

Keywords: renewable electricity production, new entrants, energy transition, energy policy, innovation, entrepreneurship, institutional theory, innovation-adoption, implementation 



\section{Acknowledgements}

Time goes fast when you are having fun. Every time I start trying to remember when I started my PhD studies, I still get amazed by how fast these two and a half years have gone. Oh, there have been some painful times along the way... but these are nothing compared to the delight of meeting many intelligent and creative people, and the fantastic feeling of getting new research ideas and of developing as a researcher. There are several people that I would particularly like to thank for making this possible.

First, I would like to thank you, Anna, for being such a great supervisor. I don't think that there is one single week that passes without my feeling like the luckiest PhD student for having you as my supervisor.

Second, Gunnel, my co-supervisor, because you provided terrific support and you always cheer me up with your good mood and your positive attitude.

Third, all colleagues at PIE, who create a working atmosphere that makes me happy (almost) every day to come to work. Above all, thank you to my $\mathrm{PhD}$ colleagues, Mohammad, Benny, and Ksenia, for all the good laughs, the nice coffee breaks and the creative discussions. Carina and Johanna, for the moral support and for being so nice and friendly. And Magnus, because if I hadn't met you or participated in your PhD course, none of this would have happened.

Last but not least, Bengt, thank you for making me believe that I can handle anything, whether it is claiming the Himalaya or changing my career. I am so lucky I found you.

Hopefully, this is only the beginning! 



\section{Table of Contents}

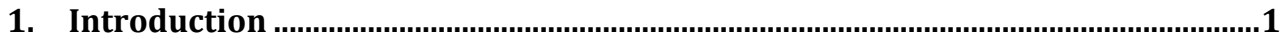

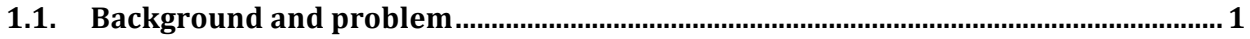

1.2. Purpose ......................................................................................................................

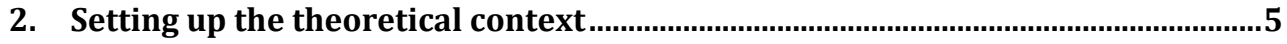

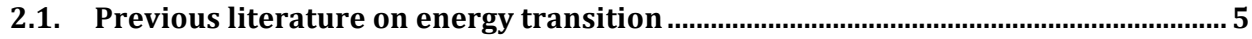

2.1.1. Previous energy policy literature.................................................................................................5

2.1.2. The technological innovation system perspective.......................................................................6

2.1.3. The multilevel perspective.....................................................................................................................7

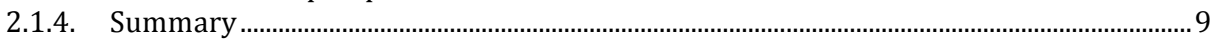

2.2. New suggested framework: an actor perspective ……………………………………... 9

2.2.1. The institutional dimension ...................................................................................................... 10

2.2.2. The entrepreneurship dimension............................................................................................. 11

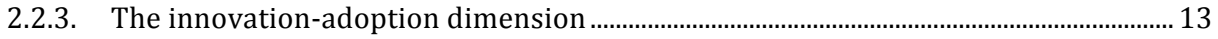

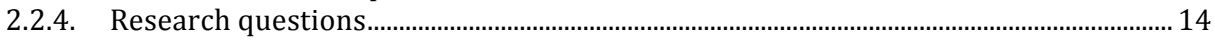

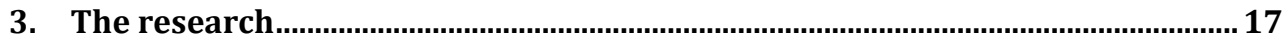

3.1. The main research project beyond the scope of the thesis........................................17

3.2. A qualitative approach ……………………………………………………………...17

3.3. Case and cross-case analysis: our base for theory building.......................................19

3.4. The contextual case: Sweden...........................................................................................20

3.5. The sampling of the new entrants ..............................................................................21

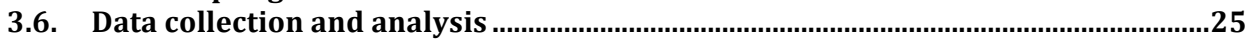

3.6.1. Data sources and collection ...........................................................................................................2

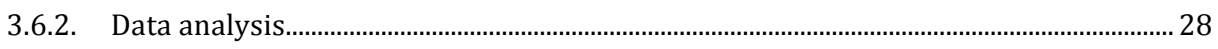

3.7. Reflections about the research process....................................................................29

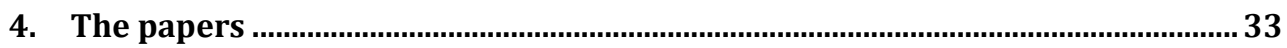

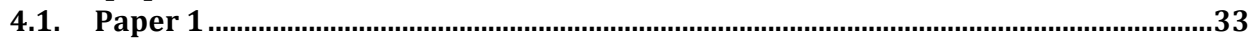

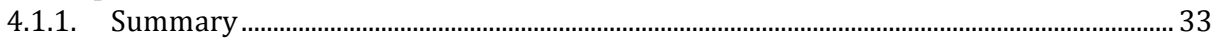

4.1.2. Authorship and publication status .........................................................................................33

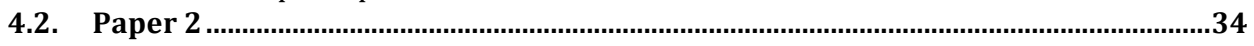

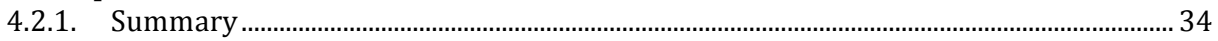

4.2.2. Authorship and publication status ...............................................................................................34

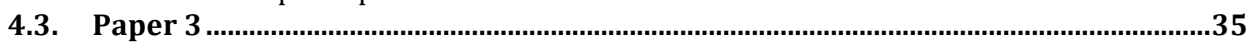

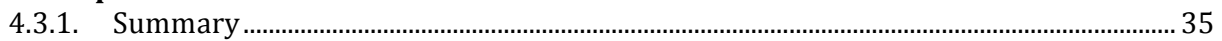

4.3.2. Authorship and publication status ..............................................................................................36

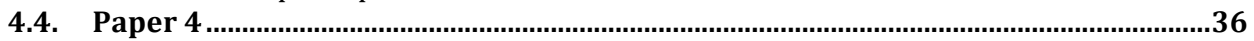

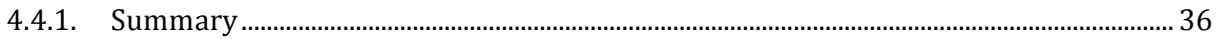

4.4.2. Authorship and publication status .......................................................................................... 37

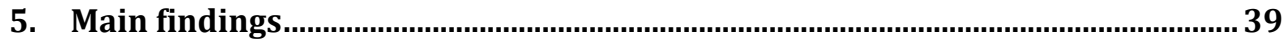

5.1. Who are the new entrants? ......................................................................................39

5.1.1. Their share within renewable electricity production …….................................................... 39

5.1.2. Their characteristics .................................................................................................................... 40

5.2. New entrants' motives and driving forces ......................................................................43

5.2.1. Motives........................................................................................................................................................... 43

5.2.2. Drivers and pressures ................................................................................................................ 45

5.3. New entrants' decision implementation: challenges and strategies ........................47

5.3.1. Challenges met by new entrants.................................................................................................... 48 
5.3.2. Strategies to cope with the challenges

6. Policy implications: what can be learned from these findings?

6.1. Scenario 1: New policies to attract and to support new entrants ..............................58

6.2. Scenario 2: New policies to secure the level and the quality of investments in

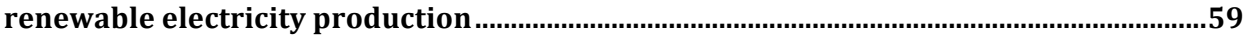

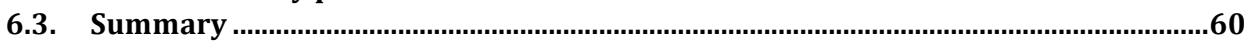

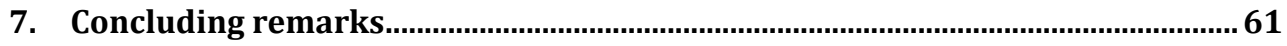

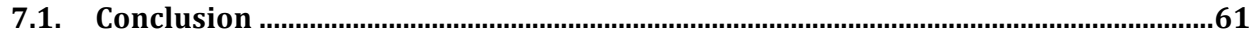

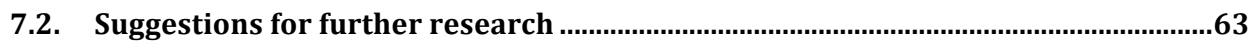

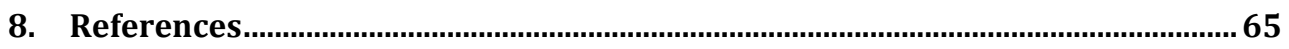


Part I 



\section{Introduction}

\subsection{Background and problem}

Managing a transition in the energy system is one of the biggest challenges of our time. While the global energy consumption is constantly increasing (IEA 2013), it is now obvious that fossil fuel reserves will not last forever. Moreover, the impact of these fuels on global warming can no longer be ignored (Dorian et al. 2006). Nuclear power was thought to be a solution to both resource scarcity and $\mathrm{CO}_{2}$ emissions, but the recent Fukushima catastrophe has served as a reminder of the potential disaster that nuclear accidents may cause (Wittneben 2012).

In this context, the diffusion of renewable electricity technologies, which are based on secure energy supplies and are almost carbon-neutral, has emerged as one potential way to reach the energy transition (Frey and Linke 2002). With the objective of encouraging their diffusion, energy policies have been developed; the locus of attention of previous literature has been on evaluating and monitoring their different impacts (Menanteau et al. 2003).

In these discussions, scholars usually consider a policy-maker perspective, and analyses are made on an aggregate level based on a number of assumptions about the producers of renewable electricity. For instance, it is assumed that these producers are incumbent actors such as large utilities (e.g. Awerbuch 2003, Bhattacharya and Kojima 2012, Pettersson and Söderholm 2009), who choose between different types of electricity production technologies (i.e., most often renewable vs. fossil-fueled) (e.g. Bode and Michaelowa 2003, Awerbuch 2006, Kahn 1996), have access to knowledge and resources (e.g. Neuhoff et al. 2008, Söderholm and Klaassen 2007), and aim at maximizing their profit (e.g. Donovan and Nuñez 2012, Finon and Perez 2007).

In reality, these assumptions do not entirely correspond to observations of the renewable electricity production market. Indeed, among the producers, there are not only incumbent actors, but also new entrants who recently joined the production market with no (or few) prior links to this activity. For instance, within the frame of its new sustainable strategy, IKEA recently invested in renewable electricity production in 
order to cover its whole electricity consumption in Sweden (IKEA 2013). Moreover, the solar power production of households has exploded over the last five years (Ueda et al. 2009). Also, an increasing number of farmers are pursuing wind power production (Sutherland and Holstead 2014). These examples suggest that, within the renewable electricity producer group, there are actors with limited access to knowledge and resources who may have implemented investment approaches different than those of the incumbent actors. Recently, some authors have, therefore, started to question the previous assumptions made about the renewable electricity technology producers and to suggest that these new types of producers may have different motives and strategies than previously assumed (Dinica 2006, Wüstenhagen and Menichetti 2012). For these new entrants, entering renewable electricity production may be a way to contribute to a better environment (e.g., households investing in solar PV), a marketing strategy (e.g., IKEA), or simply a way to decrease their electricity costs (e.g., farmers).

These empirical observations suggest that the assumptions made by previous literature may be incorrect. This may have large policy implications because, on the one hand, identification of the mechanisms that led new entrants to pursue renewable electricity production may lay the foundation for the development of policies, attracting even more of these new entrants (Wüstenhagen and Menichetti 2012). On the other hand, having new entrants on the production market may lead to implementation problems, competition for places to install and build new plants, or the creation of bottlenecks in the administration of projects, among other difficulties. There is, therefore, a need to study the renewable electricity production from an actor perspective in order to find out more about these new entrants and their entry processes.

For that purpose, three aspects are especially critical to investigate. First, the potential heterogeneity of new entrants, both in terms of characteristics and motives, should be studied. Indeed, if the new entrant group is as heterogeneous as the empirical observations suggest (e.g., large companies such as IKEA, households, and farmers), various types of new entrants might respond differently to energy policies. Second, their motives for entering the renewable electricity production market, as well as the initial influences that inspired their decision to invest, should also be understood. This is important in order to evaluate the impact of current policies and to identify potential instruments that might encourage additional new entrants to join the production or 
prevent them from doing so. Finally, given their apparent lack of previous experience in energy production, it can be assumed that new entrants face a number of challenges during the development of their projects. It is, therefore, imperative to study the process through which new entrants develop their projects, from the first idea to the completion of the project, in order to identify the challenges that confront them, as well as the strategies that they develop to handle those challenges.

\subsection{Purpose}

The purpose of this Licentiate thesis is to study the new entrants of renewable electricity production in order to identify their motives, their responses to policies, and their challenges. Based on these findings, policy implications will be drawn. 


\section{Setting up the theoretical context}

In the following sections, previous literature on energy transition is first presented. After that, I suggest a new framework, designed from an actor perspective, which therefore, may contribute to a better understanding of new entrants involved with renewable electricity production. At this stage, I also introduce the research questions of the thesis.

\subsection{Previous literature on energy transition}

In this section, the previous literature on energy transition is introduced. I start by reviewing the energy policy literature, which discusses the different economic mechanisms leading to energy transition. After that, I present two theoretical perspectives (i.e., the technological innovation system perspective and the multilevel perspective), which consider the complexity of energy transition by acknowledging different components of the energy system and the dynamics between them.

\subsubsection{Previous energy policy literature}

In previous energy policy literature, there seems to be a consensus that the economic conditions of renewables must be improved in order to achieve the amount of new renewable electricity production required for system change (e.g. Pettersson and Söderholm 2009, Söderholm and Klaassen 2007, Khan 1986, Madlener et al. 2005): "Only if the proper incentives are provided the proper investments will be made" (Haas et al. 2011: p. 2188).

In order to evaluate these economic conditions, previous studies have compared the economic costs and potential profits between renewable electricity production and electricity production based on nuclear energy or fossil fuels (e.g. Awerbuch 2003, Bode and Michaelowa 2003, Carlson 2002, Huang and Wu 2008, Kahn 1996, Söderholm et al. 2007), or between different types of renewable energy technologies (e.g. Finon and Perez 2007, Fleten et al. 2007, Muñoz et al. 2009, Delmas and Montes-Sancho 2011).

Policies have been developed to minimize the cost differences between renewable electricity and electricity from conventional sources. Hence, a large part of the debate in the energy literature focuses on comparing the effect of different incentive policies (e.g. 
del Río and Gual 2004, Jacobsson et al. 2009). In recent years, two main economic incentives have dominated the discussions: quota-based tradable green certificate systems and fixed-price/tariff feed-in systems (Menanteau et al. 2003).

This discussion mostly takes a policy-maker perspective and is based on several assumptions. First, it assumes that the actors producing renewable electricity constitute a homogeneous group of actors, mostly utilities or other incumbents of the energy market (i.e., actors who are well integrated on the electricity production market and have access to knowledge and resources) (e.g. Fleten et al. 2007, Kangas et al. 2011). Second, these actors are assumed to be economically rational; in other words, it is expected that they will invest in renewable electricity production if the economic incentives are high enough (e.g. Faúndez 2008, Haas et al. 2011, Söderholm and Klaassen 2007).

These assumptions have, however, been criticized recently by a more behavioraleconomics-oriented school within the energy policy literature (Dinica 2006, Wüstenhagen and Menichetti 2012), which argues that the group of actors investing in renewable electricity is not homogeneous, but instead composed of those who differ in terms of size, financial strength, perceptions, and key psychological characteristics and, as a consequence, vary with regard to economic rationality (Masini and Menichetti 2012, Dinica 2006, Wüstenhagen and Menichetti 2012, Langniss 1996).

\subsubsection{The technological innovation system perspective}

In comparison with the previous energy policy literature, which mostly considers economic aspects to be the answer to energy transition, another theoretical approach, the technological innovation system, considers additional aspects to explain the dynamics of transitions from fossil-fueled technologies to renewable electricity technologies.

According to this theoretical approach, new technologies emerge in a system where actors interact within a common institutional context (Jacobsson and Johnson 2000, Johnson and Jacobsson 2001, Carlsson and Stankiewicz 1991). Technological innovation systems are complex, and components of the system are interrelated; therefore, looking 
at only one component of the system (e.g., policies or economic competitiveness) will not explain how new technologies emerge, improve, and diffuse in society.

In order for new technologies, such as renewable electricity technologies, to emerge, diffuse, and transform the energy system, a number of functions are needed: the creation and diffusion of "new" knowledge, the guidance in the search for technological alternatives, the supply of resources (e.g., capital and competencies), the creation of positive external economies (i.e., market and non-market), and the formation of markets (through, for instance, policy incentives and new legislations) (Johnson and Jacobsson 2001). All of these functions play a role in the success of the technological innovation system transformation (Johnson 2001).

In the technological innovation system analysis, actors are very important as they represent one of the three elements (in addition to networks and institutions) that compose the system (Jacobsson and Bergek 2004). Together, these elements generate, use, and diffuse the new technologies (Carlsson and Stankiewicz 1991). New technologies are diffused within the system because the user-actors make the choice to adopt them (or not) at different points of time (i.e., they can be prime movers or decide to adopt at a later stage). Contextual aspects of the system, such as policies or norms and values, can influence these various choices and the points in time when those choices are made (Jacobsson and Johnson 2000).

Although the technological innovation system perspective acknowledges the central role played by actors within the system and their agency in making technical choices, this literature has focused on the emergence of new technologies and the actors participating in that process (e.g., prime movers, dominant actors, or policy actors). The process of mass-diffusion of the technology (i.e., how and why new entrants adopt and use the technology) and the perspective of the demand-side actors (i.e., users of the technology) are yet to be explained.

\subsubsection{The multilevel perspective}

Similarly to the technological innovation system perspective, the multilevel perspective adopts a systems perspective to study the dynamics taking place during technological transitions (Rip and Kemp 1998, Geels 2002). According to this theoretical perspective, 
these dynamics occur within and between three levels of the system: the micro-level (i.e., the niches), where new technologies emerge and are developed; the meso-level (i.e., the regime), consisting of incumbent actors, norms and values, laws, regulations, and infrastructure; and finally, the macro-level (i.e., the landscape), which represents the environment of the system. New technologies emerge and are developed in the niches by dedicated engineers and networks of supporting actors. For the new technologies to be adopted, the current regime (which is, by definition, conservative) must be destabilized by the landscape in order to create windows of opportunity for the new technologies to enter. This creates a regime shift, where the new technologies become the norm. In the long term, regime shifts influence changes in the landscape (Geels 2002, Geels and Schot 2007).

Despite some criticism regarding the lack of concern for actors within the system (e.g. Genus and Coles 2008), the multilevel perspective acknowledges that "only in association with human agency, social structures and organizations does technology fulfill functions" ( $p$ 1274, Geels 2002). Examples of actors who are mentioned in the approach are policy-makers and large incumbent companies (on the regime level), or the engineers developing the new technologies and their supporters (on the niche level).

For a technological transition toward renewable electricity technologies to occur, factors at the landscape level (e.g., changes in the natural environment or European and international agreements of environment targets) must pressure the regime in order to create windows of opportunity for the new technologies to be adopted. It is unclear, however, where the adopters and users of new technologies (i.e., the actors focused upon in this thesis) are situated in this process. They are neither the developers of the technologies or the supporting actors situated in the niches, nor the conservative incumbents of the current regime.

Some attempts have been made to explain the dynamic interactions between actors and the influences of these interactions (Geels 2004), but the focus has been on actors of the existing regime. The result of creating this window of opportunity and establishing a new regime (i.e., the appearance of new entrants and the method by which new technologies reach mass-diffusion) has not been explained yet. 


\subsubsection{Summary}

As described in this review of the previous literature on energy transition, despite substantial attempts to explain how and why renewable electricity technologies diffuse, the perspective of the new entrants (also seen as new investors in the energy policy literature, as new users or demand-side actors in the technological innovation system perspective, or as new regime actors in the multilevel perspective) is yet to be considered.

Recent behavioral economics literature suggests that, even if an economic dimension should be considered for a better understanding of the new entrants of renewable electricity production, economic rationality and economic motives should not be assumed for all of them. Moreover, as suggested by the technological innovation system perspective and by the multilevel perspective, energy transition must be recognized as a complex process influenced by system-level aspects, not merely policy or economic aspects. Consequently, I suggest that additional efforts be made to understand the individual actors of the potential new system by considering the new entrants' perspective with regard to mass-diffusion of renewable electricity technologies. In the following section, I introduce a new framework to study energy transition from the new entrants' perspective. In addition to the economic dimension already developed by other scholars in the energy policy literature, I submit that three other dimensions will provide additional pieces of the puzzle by providing insight into new entrants' motives, responses, and implementation challenges.

\subsection{New suggested framework: an actor perspective}

In the study of the new entrants in the renewable electricity market, I claim, as suggested in the emerging behavioral economics literature on energy policies, that the economic dimension is too narrow a scope to explain the entry motives and processes. Instead, in order to obtain the complete picture and fully understand these new entrants, I suggest that there are three additional dimensions to consider (Figure 1). In the following sections, I will describe the three new dimensions, and based on this framework, introduce the research questions of this thesis. 


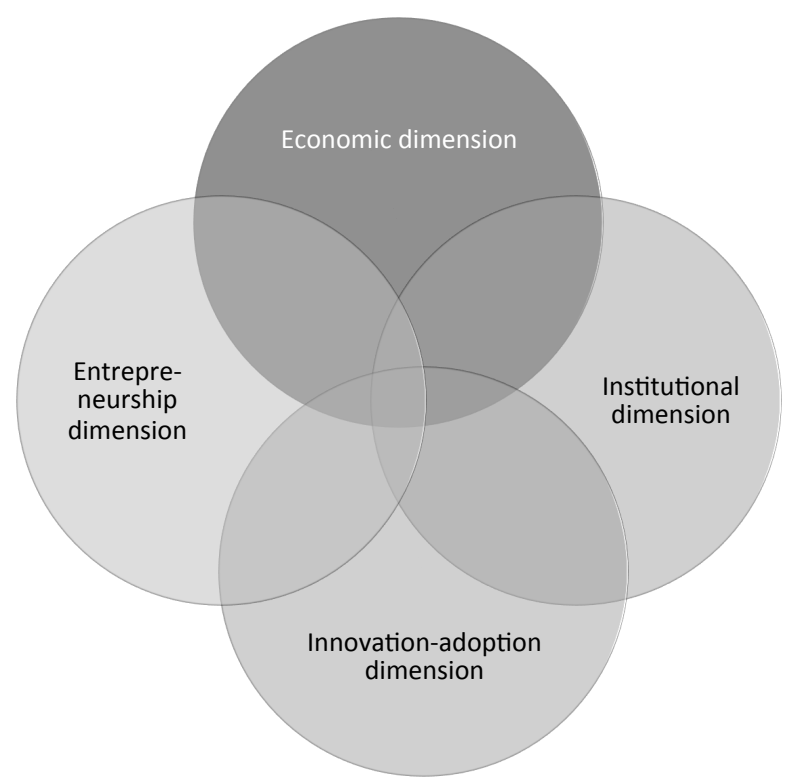

Figure 1. Suggested framework for the study of new actors in renewable electricity production.

\subsubsection{The institutional dimension}

Instead of claiming that actors are bound by rationality, as assumed in the economic dimension described in Section 2.1.1., the institutional dimension states that actors make decisions that may be rational for them although not necessarily rational for others, such as policy-makers or economists (Selznick 1996). These decisions, however, are themselves influenced by internal and external institutions (Scott 1995, Munir 2002).

Internal and external institutions create different types of pressure: regulative (e.g., rules, regulations and laws, government policy, infrastructural constraints, or bureaucratic requirements), normative (e.g., norms and values, or need of legitimacy) or cognitive (e.g., belief systems or cultural frames) (e.g. Scott 1995, Munir 2002). These pressures can take place on the individual-actor level or on the network level (Oliver 1997).

Actors can react in different ways to this variety of pressures. For instance, they tend to be more proactive if the regulations are liberal (e.g., incentive policies) rather than impeding (e.g. Ashford 2002, Sharma 2000). If normative pressures are high, they may break with societal norms or make seemingly non-rational choices in order to gain 
legitimacy from their network or from the rest of the society (Scott 1995, Oliver 1991). Likewise, under cognitive pressures, an actor with strong sustainability values or a strong aversion to nuclear power may decide to invest in solar power based on convictions, not economic profit.

In comparison with the economic dimension, the institutional dimension addresses new potential answers with regard to new entrants' driving forces and motives. Consideration of this dimension may, therefore, provide a broader range of explanations for the new entrants' decisions to produce renewable electricity despite a lack of knowledge and experience in the field.

By considering the numerous possible responses to institutional pressures, the institutional dimension also acknowledges the potential differences (for instance, different norms and values or networks) within the new entrant group as well as the consequences that these differences may have with regard to the entrants' responses to policies and the challenges that they face.

However, none of the institutional or the economic dimensions really address the fact that the actors of this study are new on the market or the fact that they somehow eschewed their routines to pursue a new business area. The institutional dimension, especially, neglects to consider the actors' desire to stand out from the masses; instead, it stresses the actors' need for conformity in order to explain their sometimes nonrational choices (e.g. Zucker 1987). Since one of the main enquiries of this study is to understand why actors with little or no knowledge or experience in the field of energy decide to enter the renewable electricity production market, it is crucial to render a dimension that actually explains this phenomenon. There is, therefore, a need to complement the aforementioned dimensions with the following ones.

\subsubsection{The entrepreneurship dimension}

The entrepreneurship literature has one notable particularity: it studies the reasons why individuals start new businesses and how these individuals recognize opportunities. The decision to start something new (e.g., a new business or an investment) is described here as a process that starts when an opportunity has been identified and when the value of exploiting that opportunity has been evaluated as 
sufficient for the entrepreneur to risk pursuing it (Shane and Venkataraman 2000, Casson 1982). Some entrepreneurs discover opportunities by chance (Kirzner 1997), while some others actively search for them (Shook et al. 2003).

There are several explanations why some entrepreneurs recognize opportunities, whereas other individuals do not. One explanation is related to entrepreneurs' characteristics, such as prior knowledge (e.g. Baron 2006), psychological characteristics (Alvarez and Busenitz 2001), networks (Ucbasaran et al. 2009), and interests (e.g. Ardichvili et al. 2003, Guth and Ginsberg 1990). Another explanation is related to entrepreneurs' goals and driving forces (e.g. Fitzsimmons and Douglas 2011). As in the economic dimension described in previous energy policy literature, the economic value of the opportunity has traditionally been presented as the main driving force of entrepreneurs (e.g. Casson 1982, Schumpeter 1934, Kirzner 1973). However, in recent entrepreneurship literature, the concept of the social entrepreneur has received considerable attention (for an extensive review, see Peredo and McLean 2006). Entrepreneurs may also be driven toward an opportunity by a desire to induce social and environmental change (e.g. Zahra et al. 2009, Hockerts and Wüstenhagen 2010).

Once the opportunity has been recognized and the decision to pursue has been taken, the exploitation phase starts. During this phase, entrepreneurs evaluate and decide under what form they will proceed, for example, through the creation of a new organization, within their existing organization, or by selling the opportunity to another organization (Shane 2003). They also gather and combine the resources needed to exploit the opportunity, such as knowledge and capital (e.g. Alvarez and Busenitz 2001). In most cases, entrepreneurs acquire some resources from external sources (e.g., through partnerships) (e.g. Hitt et al. 1997) or networks (e.g. Birley 1985), since usually, they themselves do not have access to all of the resources (Shook et al. 2003, Ucbasaran et al. 2009). This acquisition can be challenging, because new entrepreneurs may lack the networks and the legitimacy to facilitate this process (Aldrich and Fiol 1994, Brush et al. 2001). Here again, entrepreneurs' characteristics (e.g., experience, skill set, and organizational complexity) directly affect the way resources are gathered and combined for the exploitation of the opportunity (Schoonhoven et al. 1990, Hannan and Freeman 1989). 
The entrepreneurship dimension directly tackles the fact that the actors in our study are new in the field. By considering their characteristics and motives, this dimension may provide a better understanding of their reasons for entering the market and choosing to adopt new technologies, despite having little or no previous knowledge or experience in energy production. Another contribution of the entrepreneurship dimension is that it sees every entrepreneur and the corresponding exploitation process as unique, and hence, considers the potential heterogeneity of the new entrant group as well as the consequences that this may have on their investment design. Finally, because the entrepreneurship dimension considers the process of gathering and combining resources, attention may be drawn to the potential challenges faced by new entrants as well as their ability to handle these challenges, despite a lack of legitimacy and market network.

Even though the entrepreneurship dimension explores the position of the new entrants on the renewable electricity market, the relation between them and the new (for them) renewable electricity technologies is not considered in the entrepreneurship dimension. Entrepreneurs are either the developers of the innovation (Schumpeter 1934) or newcomers on existing (but imperfect) markets (e.g. Cohen and Winn 2007). This is precisely what is addressed through the last dimension of the framework, that is, the innovation-adoption dimension.

\subsubsection{The innovation-adoption dimension}

The innovation-adoption literature studies the new users of technologies or services by looking at the process that they follow when adopting and implementing an innovation. According to this dimension, characteristics of adopters, in terms of prior knowledge and experience as well as access to information and networks, have a direct impact on the innovation-adoption process (MacVaugh and Schiavone 2010). This process starts with innovation-adopters first receiving or actively gathering information about the innovation (e.g., through their networks or through early adopters of the innovation). Through this information, they then develop an opinion about the innovation, and later decide whether or not to adopt and implement it (Rogers 1962). Following the same line of argument, the characteristics of the innovation (e.g., its compatibility with the existing infrastructure) directly influence the attitudes that innovation-adopters develop toward 
the innovation, and therefore, have a direct impact on the adoption decision (e.g. Rogers 1962).

Another locus of interest in the innovation-adoption literature is the implementation process. Although the decision to adopt is very important, the implementation process is decisive for the success of innovations (Voss 1988, Voss 1985). This process may present challenges for innovation-adopters, such as a lack of information (Linton 2002) or a complex innovation (Nord and Tucker 1987). Challenges may be minimized if the management of the adopting organization is supportive (Lucas 1978) or if external cooperation and support are available (Chesbrough 2006).

By looking at new entrants in a new light, the innovation dimension may provide a better understanding of the challenges faced by them and offer strategies to help in the implementation of technologies that are new to them. Another contribution of the innovation dimension is that, in addition to considering the potential heterogeneity of the new entrants by underlining the implications of different characteristics, it also considers the heterogeneity of the innovations by stressing the role played by the characteristics of the innovation (e.g., its complexity) in the adoption process. This particular aspect is also partially considered in the entrepreneurship dimension, which emphasizes the different values of the opportunity.

\subsubsection{Research questions}

Now that the new framework has been introduced, there are a number of directions that can be taken for a better understanding of the new entrants in renewable electricity production (Figure 2). With regard to their heterogeneity, the entrepreneurship and the innovation-adoption dimensions stress the fact that new entrants (i.e., entrepreneurs and innovation-adopters) are unique. Their uniqueness and their characteristics are the reasons why some entrepreneurs recognize the value of opportunities (e.g. Baron 2006, Ardichvili et al. 2003) and why some actors decide to adopt the innovation earlier or later (MacVaugh and Schiavone 2010). Together, the two dimensions point to a number of insightful aspects, such as personal characteristics, interests, individual goals, networks, and prior knowledge. These features can be further evaluated among the new entrants of this study. 


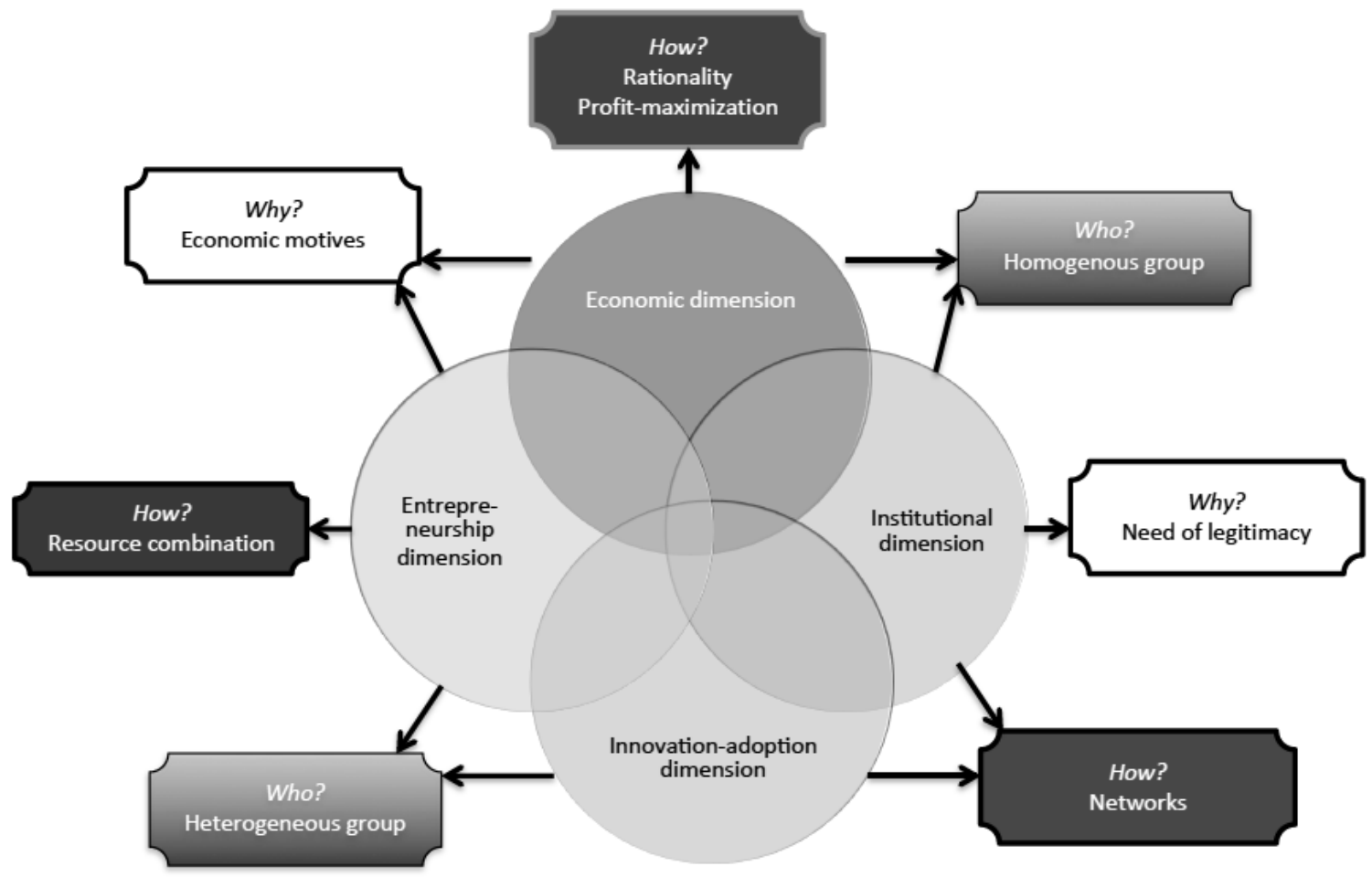

Figure 2. Different directions provided by the four theoretical dimensions of the framework.

With regard to new entrants' motives, the dimensions of our framework underline different motives that may drive actors to start the new production activity. The economic and entrepreneurship dimensions mostly highlight economic motives (e.g. Schumpeter 1934, Haas et al. 2011), while the institutional dimension claims that actors strive for legitimacy (e.g. Scott 1995). Likewise, regarding new entrants' driving forces and responses to pressures, the economic perspective assumes that actors react in a rational way (e.g. Haas et al. 2011), driven by profit maximization, whereas the other dimensions acknowledge that cognitive differences factor into the decision-making process (e.g. Selznick 1996). In the latter instance, pressures can come from networks (e.g. Ucbasaran et al. 2009) or from the actors' environment (e.g. Guth and Ginsberg 1990).

Finally, with regard to the implementation process, the four dimensions show that the characteristics of new entrants, their motives, and their driving forces influence the way they plan and design their projects. The innovation-adoption perspective, for instance, 
claims that characteristics such as prior knowledge or access to information are more likely to lead to better choices in terms of implementation (e.g. Linton 2002). If they are instead driven by legitimacy, as described in the institutional dimension, they are more likely to implement their project to reflect what is expected of them by their networks (e.g. Hoffman 1999, Zucker 1987).

During the implementation phase, different dimensions stress various challenges that can confound new entrants. The economic dimension points out access to financial capital or risks (Awerbuch 2003, Kahn 1996), whereas the entrepreneurship and innovation-adoption dimensions highlight challenges related to access to knowledge and skills (e.g. Alvarez and Busenitz 2001). Similarly, the institutional perspective stresses the challenges related to the lack of legitimacy of new entrants (Scott 1995).

Using the theoretical background described above as a base, the research questions can now be defined:

RQ1: Who are the new entrants within the group of renewable electricity producers?

- What are their characteristics?

- How do they differ from each other?

RQ2: What are the motives of the new entrants?

- What motivates their decisions to start producing renewable electricity?

- To what extent are they pressured or driven by current policies?

RQ3: What are the challenges that these new entrants face, and how do they handle them?

- What is the impact of their characteristics, motives, and driving forces on the implementation of the renewable electricity technologies?

- How do they obtain access to resources, including knowledge, financial resources, and legitimacy? 


\section{The research}

In this section, I describe the methodological choices that I made, which allowed me to reach the results presented in the following section. For each methodological choice presented, I consider the consequences regarding the reliability and generalization of the results.

\subsection{The main research project beyond the scope of the thesis}

The research conducted in this thesis has been executed within the frame of a larger project, i.e., "New Investors in Renewable Electricity Production: motives, investment criteria and policy implications," which is financed by the Swedish Energy Agency. This project has two main objectives. The first objective is qualitative: to explore new entrants in renewable electricity production with regard to their motives, driving forces, and investment processes in order to evaluate the impact of current policies and to suggest potential new policies. The second goal is quantitative: to increase the generalizability of the findings by utilizing a survey to test the propositions that emerged from the qualitative study.

This thesis presents the results of the first part of the project, i.e., the qualitative study. The second part of the project, i.e., the quantitative study, will be performed after the completion of this Licentiate thesis. I will reflect further on the future methodological steps when discussing the limitations of the methodological choices that have been made thus far and when proposing recommendations for further research.

\subsection{A qualitative approach}

Since the ambition of this research was exploratory and the goal was to generate new theory, as opposed to testing existing theory (Gersick 1988), I have used qualitative methods throughout the research process of this thesis.

I chose to collect and analyze the data through qualitative methods for several reasons. First, even if it were assumed that the new entrants of the study differed from the traditional group of actors, the exact types of differences were unknown. It was, therefore, necessary to establish qualitative contact with these actors in order to determine their different characteristics. 
Second, one goal of the research was to understand the entry process of the new producers. For that, the qualitative method was particularly appropriate since it gives people the freedom to describe their process from their viewpoint, instead of forcing them to label it as a predefined process (Patton 1990). As explained by Miles and Huberman (1994), one of the strengths of qualitative data is their "richness and holism" (p10), as they provide extensive descriptions of complex processes.

Finally, since the topic of the research was related to aspects such as driving forces, motives, external influences, and challenges, it must incorporate the perceptions of the new entrants. Qualitative research is particularly well suited to clarifying people's perceptions, assumptions, prejudgments, and presuppositions (Patton 1990, Van Manen 1977).

Qualitative methods also have weaknesses that need to be addressed. First, in qualitative data collection, the researcher is the instrument. On the one hand, this may be seen as an advantage, since it gives the researcher the possibility to access the study objects' perceptions. On the other hand, it is a disadvantage because perceptions are easily affected and transformed. This can concern both the perceptions of the researcher in collecting and analyzing the data, and the perceptions of the study objects when answering questions. Some interviewees may, for instance, be tempted to answer questions in a way that correlates with the researcher's expectations (Miles and Huberman 1994). For that reason, it was important to analyze the totality of the data collected in the interviews instead of analyzing the responses to each question individually. Considering the interview as a whole made it possible to analyze the consistency of the answers through, for instance, the triangulation of questions (i.e., I asked some of the questions several times in different formulations), and to ask followup questions (e.g., in addition to asking them about their motives for investing, I asked how they got the idea and how they made their implementation decision) in order to perform cross-data validity checks (Patton 1990). It is the crossing of the data and the patterns that emerged that are presented as findings in this thesis and in the attached papers, not the stories told by interviewees.

Advocates of quantitative methods also argue that one weakness of the qualitative method is its difficulty generalizing, because it includes only a small sample of the study 
objects (Eisner and Peshkin 1990). In this context, "How can we be sure that a[n] 'earthy', 'undeniable', 'serendipitous' finding is not, in fact, wrong?' (Miles 1979: , p590). My strategy in this thesis has been to collect a large number of cases of new entries, which is the phenomenon that is being studied. By selecting cases that reflected the complexity of the new producer group and by conducting semi-structured interviews that allowed for follow-up questions, I claim to have covered the process of a significant sample of study objects in depth, resulting in data that are reliable and generalizable (at least for the study of new entrants in renewable electricity production in Sweden). However, in order to increase the generalizability, I plan, as explained in Section 3.1., to use a quantitative survey to test the propositions that emerged from the quantitative study. In addition, I plan to add the case of another European country to the case of Sweden.

\subsection{Case and cross-case analysis: our base for theory building}

The study of the new entrants within renewable electricity production is based on a case study of new entrants in Sweden. The aim is to use this contextual case (i.e., Sweden) and the cases of the 37 new entrants to intuitively identify emerging patterns across the cases and, therefore, proceed to theory building (Eisenhardt and Graebner 2007, Yin 1984).

The main strength of the case study methodology is that it provides rich empirical data that provides the researcher with the possibility to conduct in-depth analyses (Yin 1984). Richness and in-depth, detailed narratives have the power to broaden our understanding of the human condition (Weick 2007).

However, case studies can sometimes be misunderstood by scholars or readers who are more familiar with large-scale hypothesis testing and who may consider case study research to be less precise, less objective, and less rigorous. It is essential, therefore, that I underline the fact that the goal of this research is theory building, not theory testing (Eisenhardt and Graebner 2007).

Moreover, case study research is often criticized for its theoretical, rather than statistical, sampling methods (Eisenhardt 1989, Eisenhardt and Graebner 2007, Yin 1984). In this study, the case of Sweden was selected because I had access to very 
complete data, as complete as that compiled in most research methods. Focusing on one study context may, of course, raise questions regarding the generalizability of findings; this will be addressed in the following section (3.4.), where I will more explicitly explore the motivation of the specific case choice and the implications of this choice. With regard to the 37 cases of entry processes, the selection was made in order to "replicate previous cases [, to] extend emergent theory, or [...] to fill theoretical categories and provide examples of polar types" (p537) (Eisenhardt 1989). I will describe this process in more detail in Section 3.5.

In the study, I performed a cross-case analysis among the 37 cases of new entrants and used each new entrant case to replicate, contrast, and extend the emerging theory (Yin 1984). The use of multiple case studies refutes most of the criticism previously cited against case-study methodology in the sense that it ensures the testability and the validation of the results and of the theories developed. Through cross-case development and analysis, intuitive theories and patterns emerge. These are continuously tested and measured in the empirical setting and later in the literature, thus securing the possibility of verifying and replicating the results (Eisenhardt 1989). In section 3.5, I describe in detail the collection and analysis processes of the study.

\subsection{The contextual case: Sweden}

As explained in Section 3.1., the primary study context of the research, i.e., Sweden, was defined by the sponsor of the main research project. This may be interpreted as a methodological limitation (since the choice of the case was imposed), but there are, in fact, a number of reasons why the choice of Sweden is particularly relevant for the study of the new entrants within renewable electricity production.

First, the availability of reliable data made the choice extremely relevant. Indeed, almost all renewable electricity producers in Sweden are included in the Swedish tradable green certificate system. The list of organizations and anonymized private persons is public and available on the Swedish Energy Agency's website. Second, the electricity production market in Sweden has been liberalized since 1996, which makes it possible for new entrants to start their own electricity production and to decide which type of electricity source(s) this production should be based on. Finally, Sweden has had a tradable green certificate system since 2003. The objective of this system is to support 
the production of renewable electricity by allocating certificates to the producers of renewable electricity (i.e., including, with some restriction, wind power, solar power, wave power, geothermal power, biomass-based power, peat in combined heat and power plants, and hydro power ${ }^{1}$ for each MWh produced and sent to the grid. These certificates can be sold to electricity distributing companies and to energy-intensive companies, which have yearly quotas of certificates that they are legally obliged to buy. This policy instrument is market-based, building on the assumption that investors will be rational by choosing the cheapest and most efficient technologies (Stavins 2003), which is precisely the type of assumption that I intend to challenge in this study. There is, therefore, a great deal to be learned by observing the extent to which new actors actually match these assumptions and respond to this kind of economic incentive.

Having Sweden as our case may have some implications for the generalizability of the empirical findings. First, the market composition, i.e., the types of new entrants and their characteristics, may be different in other geographical settings. However, previous studies conducted in other geographical regions, e.g., the UK (Toke 2005b, Tate et al. 2012) or Germany (Langniss 1996), suggest that new entrants similar to those identified in this study exist and that our results, therefore, may be generalized to other settings. In the scope of this thesis, I did not have the opportunity to perform similar studies in other countries in order to strengthen the generalization potential. However, at a later stage, I do intend to study new entrants into renewable electricity production in another European country in order to compare the findings from two geographical contexts, thereby increasing the generalizability. Of course, that objective lies beyond the scope of this thesis.

\subsection{The sampling of the new entrants}

Unlike case studies of companies or organizations, for instance, where several interviews are usually conducted with different members of the organization in order to provide a complete understanding of the company (e.g. Eisenhardt and Bourgeois 1988), I did not interview the different new entrants to acquire their perspectives on the same study object (e.g., a company or an organization), but rather to acquire insight into the

\footnotetext{
${ }^{1}$ Currently, however, there are no wave or geothermal power plants and only a few solar photovoltaic
} 
phenomenon (i.e., the entry process of new entrants). As such, each interview with the new entrants should be considered an individual case of new entry.

For the first step of the sampling, the cases of new entrants were chosen in order to create a representative population on which the analysis would be based. The goal here was to control irrelevant variation and to define the limits of the population in order to be able to generalize the findings (Eisenhardt 1989). The selection of cases to create representativeness is quite unusual for building theory from case studies, but it has been done in previous studies, which have received attention for being particularly strong in terms of methodology (e.g. Eisenhardt 1989, Ferlie et al. 2005).

In order to control for characteristics such as main business activity and organizational form in new entrants' driving forces, implementation processes, and potential challenges, a typology of the renewable electricity producers was made based on the data on actors within the tradable green certificate system available from the Swedish Energy Agency. Using the organization numbers and the name of the organizations, I gathered information pertaining to the form (e.g., company, economic association, or municipal organization) and the main activity (e.g., farming, energy, or renewable project developing) of the producers. From there, patterns emerged from the data and a number of subgroups of new entrants were identified (Table 1). Also, subcases were identified to include all types of new entrants (Table 2). Some types of actors were absent (or were present in limited numbers, compared to the total population) in some categories. There were, for example, no project developers in hydropower or solar power, and there were only 28 associations and only 26 farmers within hydropower. Since the information about sole traders had been anonymized by the Swedish Energy Agency in accordance with Sweden's current law regarding the protection of personal data $^{2}$, sole traders could not be identified. This explains why no interviews were conducted in some categories (Table 2).

\footnotetext{
2 Personuppgiftslag (1998:204)
} 


\section{Table 1}

The actors of the renewable electricity production in Sweden

\begin{tabular}{|c|c|}
\hline Types of actors & Description \\
\hline Incumbents & $\begin{array}{l}\text { State- or privately owned utilities, privately owned } \\
\text { energy companies and municipal energy companies who } \\
\text { owned the transmission and distribution networks for } \\
\text { electricity, the local district heating systems, and the } \\
\text { majority of the electricity production capacity prior to } \\
\text { the liberalization of the electricity market in Sweden. } \\
\text { Their electricity production is based on both renewable } \\
\text { and conventional energy sources. }\end{array}$ \\
\hline $\begin{array}{l}\text { Publicly owned non-energy companies or } \\
\text { organizations }\end{array}$ & $\begin{array}{l}\text { Companies or organizations owned or controlled by } \\
\text { national, regional, or municipal governments, with a } \\
\text { main area of business other than energy. }\end{array}$ \\
\hline Independent Power Producers (IPPs) & $\begin{array}{l}\text { Privately owned companies whose main business area is } \\
\text { electricity production. }\end{array}$ \\
\hline Farmers & $\begin{array}{l}\text { Privately owned companies, sole traders, or } \\
\text { partnerships whose main area of business is agriculture } \\
\text { (e.g., grains or animal keeping). }\end{array}$ \\
\hline Diversified companies & $\begin{array}{l}\text { Privately owned companies with a main area of business } \\
\text { other than energy production (e.g., pulp and paper). }\end{array}$ \\
\hline Power project developers & $\begin{array}{l}\text { Privately owned companies whose main area of } \\
\text { business involves planning, building, and initially } \\
\text { operating power plants for other owners. }\end{array}$ \\
\hline Sole traders & $\begin{array}{l}\text { Individuals or partnerships owning one or several } \\
\text { power production plants; they may specialize in this } \\
\text { field or possess another main area of activity. }\end{array}$ \\
\hline Associations & $\begin{array}{l}\text { Associations that own one or several power plants; they } \\
\text { may specialize in this field or possess another main area } \\
\text { of activity. }\end{array}$ \\
\hline
\end{tabular}

Once the initial sample had been selected, one of my supervisors (Anna Bergek or Gunnel Sundberg) and I conducted interviews with 4 actors of different types, who were producing electricity from different energy sources (More details about the data collection process will be supplied in the following section.). Once these interviews had 
been conducted and transcribed, it became obvious that the new entrants' driving forces and implementation strategies did not correlate with the implicit predictions based on the previous energy literature. Moreover, no driving force or implementation patterns could be found among actors of the same type or among actors who had adopted the same renewable electricity technology (i.e., wind power, hydropower, solar power, or biomass-based power). New subcases, therefore, needed to be added to the initial sample. This sampling was conducted theoretically, and subcases were chosen in order to provide examples of polar types and to replicate previous cases (Eisenhardt 1989). I added a total of 30 subcases (whom I interviewed on my own), and stopped once the results began to lack new information and once the emerging patterns became consistent (Eisenhardt and Bourgeois 1988, Gersick 1988). Overall, I conducted 37 interviews (Table 2).

Table 2

Overview of the subcase sample per actor type and energy source

\begin{tabular}{|c|c|c|c|c|c|}
\hline & Wind power & $\begin{array}{l}\text { Biomass- } \\
\text { based } \\
\text { power }\end{array}$ & $\begin{array}{l}\text { Hydro } \\
\text { power }\end{array}$ & Solar power & Total \\
\hline IPPs & 5 & 0 & 1 & 1 & 7 \\
\hline Farmers & 3 & 2 & 0 & - & 5 \\
\hline Associations & 3 & - & 0 & 1 & 4 \\
\hline $\begin{array}{l}\text { Diversified } \\
\text { companies }\end{array}$ & 7 & 4 & 1 & 1 & 13 \\
\hline $\begin{array}{l}\text { Project } \\
\text { developers }\end{array}$ & 4 & - & - & - & 4 \\
\hline $\begin{array}{l}\text { Publicly owned, } \\
\text { non-energy } \\
\text { companies }\end{array}$ & 2 & 3 & 0 & 1 & 6 \\
\hline Total Interviews & 24 & 8 & 2 & 3 & 37 \\
\hline $\begin{array}{l}\text { Total number of } \\
\text { actors }\end{array}$ & 558 & 71 & 292 & 15 & 936 \\
\hline
\end{tabular}

It should be mentioned that I only selected cases of actors (individuals and organizations) who had decided to enter renewable electricity production, and I did not select subcases of actors who had decided not to enter it. This decision stems from the aim of this study. The aim was not to identify the reasons why some organizations and 
individuals decide whether or not to invest. Instead, the aim was to determine the leading cause that motivated them to invest, despite the many reasons not to. In concert with this, I was interested in understanding the complexity of the new entrant group, i.e., the differences and similarities among new entrants.

For the reliability of the study, it is important to mention the possibility that the types of new entrants identified in the renewable electricity production in Sweden were, to some extent, case-dependent. Indeed, it is possible that other types of actors may emerge in another geographical context. However, the types of new entrants that were identified correspond to the types of actors that have previously been presented in the literature (e.g. Langniss 1996). It can, therefore, be assumed that the types of new entrants identified in this study are generalizable.

Finally, with regard to the incumbent actors, i.e., the actors who have been on the energy market for decades and for whom renewable electricity production is just one part of their energy production portfolio, it should be stated that the composition of this group was not studied in detail, since the focus of the study was only on the new entrants. However, even if incumbent actors are present in all contexts, one must consider the fact that in other countries, the terms incumbent or new entrant may have different meanings than in the Swedish context. Nevertheless, further research may increase the generalizability of this typology by comparing the composition of the renewable electricity producer group in other geographical contexts.

\subsection{Data collection and analysis}

\subsubsection{Data sources and collection}

The tradable green certificate database was the data source for the typology of new actors, which was the starting point of the subcase sampling. The database is available online and updated twice a year in January and in July. The July 2012 version of the database is used in the included papers. Eligibility is offered to most of the existing renewable electricity technologies: wind power, solar power, wave power, geothermal power, biomass-based power (with some restrictions), peat in combined heat and power plants, and hydro power (including small-scale plants up to $1.5 \mathrm{MW}$, new plants, renewed operation of previously decommissioned plants, and increased capacity in 
existing plants). However, the system currently includes only a few solar photovoltaic plants and no wave or geothermal power plants.

Only plants that are connected to the grid are included in the data; thus, the share of smaller plants and, consequently, the share of new entrants are likely somewhat underestimated. However, a comparison between official wind power statistics (based on voluntary reporting) and our database indicate a small difference between the two data sets (1492 wind turbines reported in the official statistics and 1550 turbines included in our database by July 2012). This indicates the clear reliability of our database. Another limitation of including only plants that are connected to the grid is that it excludes the motives of new entrants who invested in renewable electricity production in order to live off-grid because, for instance, they did not want to be dependent on large utilities, as other previous studies have highlighted (e.g. Palm and Tengvard 2011). Future research should explore the motives of new entrants who are not connected to the grid and, therefore, do not produce renewable electricity as a business activity.

I initially contacted 40 new entrants. Three of them chose not to answer questions due to time constraints. Semi-structured interviews were, therefore, conducted with 37 new entrants (Table 2). Most interviews were conducted face-to-face. These interviews usually took 120 minutes, but some lasted for 3 hours. Ten interviews were conducted in the form of telephone interviews, for various reasons: some interviewees chose not to meet me personally due to time constraints and others were situated in remote areas of Sweden. These interviews lasted, on average, 60 minutes.

All interviews were based on the same interview template (i.e., with some variations depending on the type of organization being interviewed). Since the goal was to interview the individuals who had been the main actors of the project development process, I interviewed the owner or the CEO in small companies, the chairman in associations, and the person in charge of renewable electricity production investments in large companies and municipalities. In IPPs and project developing companies, project developers working daily with the development of renewable energy projects were interviewed. 
The interviews started with factual questions related to the organization, such as the main activities, the size, and the share of renewable electricity in the turnover (i.e., only for companies). After that, factual questions concerned the renewable electricity production, such as the renewable source on which the production was based, the year production started, the installed capacity, and the average yearly production. Next, interviewees were asked to describe the ideation process, with questions related to, for instance, the point of time when the idea emerged, the context of the organization at that time, and any prior contacts with renewable energy. This part of the interview was more difficult to conduct since it required that interviewees remember a complex process that may have happened a long time ago. Subsequently, it was essential that I, as the interviewer, support the process by asking follow-up questions. In some cases, when the interviewees had to think for a long time or were not completely clear about the ideation process, I triangulated the information by returning to these questions later in the interview.

I then asked questions about the motives and the driving forces of the decision to start producing renewable electricity. Here, to support the emergence of a complex pattern of answers, questions concerned their reasons for investing, as well as the possibility of their having evaluated investments other than renewable electricity production and the reason why they considered renewable electricity production a better option. Interviewees were also asked about the choices made during the project development process, e.g., the technology or the suppliers; and about the investment calculation and strategy, e.g., the electricity price that they had based the calculation on, whether or not they had included the income of the tradable green certificate, and the estimated price or time frame compared to the level of return on the investment. After that, I asked them about the administrative design of the project, e.g., the permit application and contact with the grid owners.

The interview addressed the future, e.g., what they would do when they were no longer entitled to receive tradable green certificates or if they planned to invest in new projects. Finally, they were asked to make a recommendation to policy-makers or other decision-makers in order to facilitate the process for other new entrants starting to produce renewable electricity. 
During the first phase of the subcase collection (i.e., the first 4 subcases), we conducted the interviews in tandem, adopting complementary roles in the interviews, filling gaps in the questioning, and creating a flow in the interview process. Both interviewers took notes, and the interviews were also recorded. The goal here was to create routines and a common understanding of the interview data. In the second phase of the subcase collection, I conducted the interviews (the remaining 33) myself. The interviews were recorded and transcribed within one day of the conversation in order to avoid missing information or false interpretations, as initiated by Yin (1984) and Eisenhardt and Bourgeois (1988).

\subsubsection{Data analysis}

The primary data analyzed were the interview transcripts. This analysis followed an iterative process and took place in three main steps. During the first step, two researchers (Anna Bergek and I) independently searched for patterns in the data by underlining quotes in the transcripts, with a focus on the driving forces and motives of the new actors. After that, we individually grouped the quotes according to similar motives or driving forces. We then compared our results and consulted the literature in order to compare the emerged patterns with the patterns described in the literature.

This led us to the second step, where the same process was repeated with the focus to find patterns associated with the same motives and driving forces. From there, new patterns emerged with regard to actors' responses to external and internal pressures (Paper 2) and to actors' initial resources and resource acquisition strategies (Paper 3). Again, we consulted the literature and compared these patterns with the patterns described in previous institutional and entrepreneurship literature.

Finally, in the last step of the analysis, after noticing a link between actors' resources and actors' challenges, we returned to the interview transcripts and identified patterns. This link between resources and implementation strategies had been described in previous innovation literature; therefore, we decided to review additional innovation literature focusing on the implementation process of the innovation. This resulted in Paper 4. 
The data collection and analysis took place in parallel, over a two-year period. (Table 3), which bolsters the strength of the findings. Indeed, the patterns that emerged at the beginning of each analysis focus (i.e., motives and driving forces, internal and external pressures, initial resources and resources acquisition, and resources and challenges) were reinforced by not only the literature review, but also by additional subcases being gathered at the same time. Throughout the process, it was possible to further "confirm, extend and sharpen" the theories, hence building internal validity to the study (p533) (Eisenhardt 1989).

\subsection{Reflections about the research process}

The research conducted in this thesis has been a process that took place over two and a half years. During that time, some methodological choices have been undertaken, which I explained and discussed earlier in this chapter. There are, of course, some advantages and disadvantages with these choices.

In my opinion, the main strength of this study stands on the richness of the data collected. I met 37 new entrants, mostly in person, during extensive interviews. During that time, I was able to immerse myself in their context and to understand their realities throughout the development of their projects. This provided me with a solid understanding of the new entrant group. In this sense, the explorative purpose of the research was reached.

This richness, however, does have a drawback: at some stages of the research process, it was particularly difficult to systematize the empirical data into analyses and models. In some cases, the complexity of the data forced us to make the coding rules even clearer and to make them visible to the reader, in order to prevent ourselves from leaving room for interpretation. An example of that can be found in Paper 2, where I chose to include a table that provided the systematization of actors' motives with citations from the interviews.

Furthermore, the theoretical framework, including the four dimensions presented in Chapter 2, has strengthened the study by providing the theoretical ground of the research without excluding potential explanations. In other words, it has provided the frame of the study (Figure 1) without limiting it to one single perspective. However, 
using different perspectives to observe the same phenomenon has resulted, in some cases (especially in the study of actors' motives), in different interpretations. This explains why, for instance, in Paper 2, which considers an institutional perspective, and in Paper 3, which considers an entrepreneurship perspective, different motives for new entrants making the decision to start producing renewable electricity are highlighted. These different interpretations may be viewed as a weakness because they can create confusion for the readers. If given the opportunity to reformulate my method of analyzing empirical results, I would try to integrate the different dimensions within the same paper, focusing on the same research question, instead of using different theoretical lenses in different papers.

The choice of these four theoretical dimensions is a worthy discussion, as is the suggestion of integrating them into one framework. As I already established in Chapter 2 (Section 2.2.4.), the economic, entrepreneurship, institutional, and innovation-adoption dimensions were chosen because they are the literature streams within social sciences that best address the specific context of the new entrants (i.e., they discard their routines by entering a new market, they implement a technology that is new to them, and they exist in a context where economic incentive policies and strong environmental values interact). I claim that looking at only one of these dimensions does not suffice to gain a complete understanding of the new entrants and of their process. Therefore, these theories need to be integrated, and this integration is possible because the literature streams are connected from the start. For instance, the institutional theory and the economic theory are already integrated: economic policies are considered an economic factor in the economic theory and an institutional factor in the institutional theory. Moreover, the innovation-adoption and the entrepreneurship theories have also traditionally been linked with each other by Schumpeter, for instance, who defines the entrepreneur as someone who carries out new combinations (Schumpeter 1934).

Finally, my last reflection on the strengths and weaknesses of the study is related to its exploratory nature. Again, with a sturdy yet theoretical framework as a reliable foundation, this study is even stronger due to its lack of a structured interview matrix with close-ended questions. For instance, based on previous literature, one could have assumed that the new actors were mostly motivated by economic gain or a need of legitimacy, and directed questions toward these motives. Instead, open-ended questions 
and semi-structured interviews were chosen. In this way, I entered the field to collect data, with no previous assumptions about the new entrants. This made it possible for unexpected patterns to emerge. Focusing the questions on particular motives would not have permitted the appearance of the whole motive range (described in Chapter 5). However, as I reflect on the research process, I realize that it would have been useful to design the interviews according to some key propositions based on previous literature and on empirical observations. The semi-structured interview questions were indirectly designed this way, but the analysis process probably would have been easier if it had been based on clear propositions serving as starting points of the argumentation. 
Table 3

The data collection and analysis process

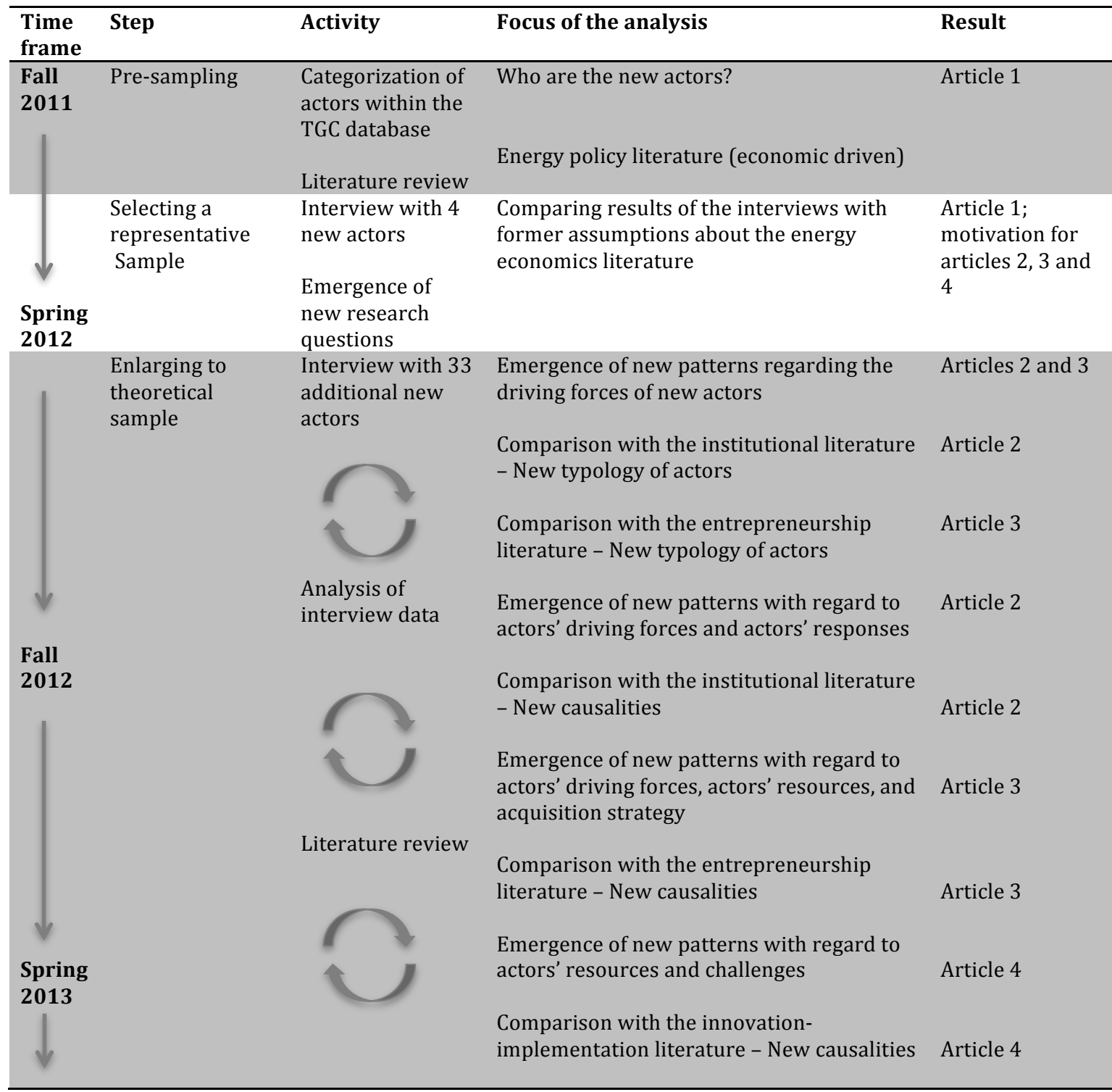




\section{The papers}

\subsection{Paper 1}

\subsubsection{Summary}

The first paper included in this thesis addresses the fact that energy policies and existing literature have traditionally assumed that the investors in renewable electricity production are utility-type investors who make rational choices to maximize the economic value of investments. By considering the segmentation of the investor group in Sweden, this paper builds on the emerging literature that underlines the fact that investors may not be a homogeneous group. The findings of the study show that investments in renewable electricity production are made, to a large extent, by new types of actors, e.g., diversified companies, IPPs, and farmers. Moreover, the findings show that the constellation of these new entrants varies depending on the technology and energy source used to produce electricity. This, in turn, shows that the picture earlier assumed by policy-makers and based on previous literature is incorrect, thereby suggesting that the previous understanding of renewable electricity producers' investment logic, as well as their motives and driving forces, may have been inaccurate.

In the paper, we advocate the need for further research about the new entrants within renewable electricity production and introduce a multidimensional framework for analyzing differences between categories of investors. This framework considers the entrepreneurship, innovation-adoption, and institutional dimensions, in addition to the economic dimension presented in the theoretical framework of the paper.

\subsubsection{Authorship and publication status}

I co-authored Paper 1 together with Anna Bergek and Gunnel Sundberg. Anna Bergek was the main author and coordinated the data analysis and the writing. The data was already available from the Swedish Energy Agency, but deep analysis was required, which Anna, Gunnel, and I performed together. Furthermore, I participated in writing the theoretical framework, the empirical findings, the analysis, and the suggestion of the framework. The four dimensions of the framework are the result of extensive discussions between Anna and me. 
After two rounds of review, the paper was published in Energy Policy in March 2013 (Bergek et al. 2013).

\subsection{Paper 2}

\subsubsection{Summary}

In Paper 2, we build on the suggestions made in Paper 1 by further studying, from an institutional perspective, the new entrants' motives and the underlying drivers or pressures leading them to make the decision to start producing renewable electricity. The paper explores the individual perspective of the new renewable electricity producers, which was heretofore missing in the literature, and also confirms what has been suggested by a few previous authors, namely that some of these new entrants are driven by other forces and are concerned with different investment logics than those previously assumed in policy literature.

We confirm that economic motives (as underlined in previous policy literature) do concern new entrants of renewable electricity production, but we also identify a number of other motives, e.g., sustainability values, an interest in the technology, and the need to solve a problem. The forces at the origin of these motives may be pressures or drivers, depending upon whether the new entrants are compliant or proactive in their responses. A particularly interesting finding is that economic incentives created by energy policies did not trigger the desire to produce renewable electricity for a majority of new entrants. Normative pressures and drivers created from actors' norms and values, need of legitimacy, or personal interests emerged as significant forces, leading new entrants to join the electricity production market.

We end Paper 2 by drawing policy implications from these findings and by underlining the need to reconsider the goals of current energy policies.

\subsubsection{Authorship and publication status}

I co-authored Paper 2 with Anna Bergek. Although all ideas and the outline of the paper are a result of common discussions and cooperation, I took the role of main author for coordinating and leading the way by, for instance, designing the frame of reference, initiating changes, and choosing the targeted journals for future publication. I also 
collected most of the data used in the paper through interviews conducted during the first two years of my PhD studies.

The paper was presented at the 3rd International Conference on Sustainability Transitions in Copenhagen in August 2012 and at the 18th Conference of the Greening of Industry Network in Linköping in October 2012. Our aim is to publish it in a journal on policy issues in 2014 .

\subsection{Paper 3}

\subsubsection{Summary}

Paper 3 studies the new entrants of renewable electricity from an entrepreneurship perspective. More specifically, it looks at the reasons why they identify renewable electricity production as an opportunity worth pursuing, despite limited knowledge and experience in the field, and how they acquire and combine the resources needed to exploit the opportunity.

In accordance with previous entrepreneurship literature, we show that the economic value of the opportunity was one of the main motives for pursuing it, but it was definitely not the only one. Some new entrants also saw, for instance, the value of fulfilling a personal interest, making good use of available resources, or solving a problem by pursuing this opportunity. Most of the new entrants were driven by personal or internal motives (i.e., fulfilling personal or internal needs) rather than by market-needs (i.e., market-driven opportunities or market-gaps).

With regard to resource acquisition and combination, we provide evidence that, among the new entrants of our study, each type had access to one or several initial resources, but had to acquire additional key resources. Some of these additional resources were more difficult to acquire than others (e.g., institutional contacts and knowledge was more difficult to acquire than financial resources or natural resources). Finally, the resource acquisition of those additional resources was less challenging when intermediary actors and existing personal networks were in place and when new entrants controlled instrumental resources that could be used to obtain other resources. 


\subsubsection{Authorship and publication status}

Paper 3 was co-authored with Anna Bergek. The typology of entrepreneurs was discussed and designed together, and I proposed the link between entrepreneurial motives and resource combination. We contributed equally to the reference frame, and I wrote most of the empirical part of the paper, while including input and revisions from my co-author. The analysis, based on common discussions, was mostly written by Anna Bergek.

This paper was presented at the $14^{\text {th }}$ International Conference of the International Joseph A. Schumpeter Society (ISS) in Brisbane in July 2012. Our aim is to complete the data collected through interviews with a survey of the whole population of the entrepreneurs of our study. The survey results will help us to provide a better contribution regarding the share of actors with different motives, and to test our propositions regarding resource acquisition and combination. The survey is scheduled to be distributed during the spring of 2014. Once the analysis is finished and the paper completed, we intend to send it for publication to a journal on entrepreneurship, hopefully at the end of 2014.

\subsection{Paper 4}

\subsubsection{Summary}

In Paper 4, I study the implementation process of new renewable electricity producers, from their decision to start producing to the beginning of production. I take an innovation-adoption perspective and consider the new entrants to be the innovationadopters of renewable electricity technologies. In the first part of the paper, I highlight the difficulties faced by adopters when implementing the technologies, and in the second part, I study the role of private intermediaries in the implementation process.

The findings show that new entrants must handle a number of challenges in the implementation process. These challenges are related to administrative processes, access to financial resources, conflicts with the local population, and a lack of market integration and knowledge, as underlined in previous literature. Despite the specificity of the renewable electricity innovation context, the local context of innovation- 
implementation may be generalized to other implementation contexts, and to other types of innovation.

In the studied cases, intermediaries acted as key players in the innovation-adopters' implementation processes. Depending on the needs of the new entrants, intermediaries acted as knowledge-experts, mediators, market-integrators, or implementation substitutes. Despite the role that private intermediaries can play in facilitating the implementation, the lack of control felt by some new entrants during the implementation process suggests a vulnerability that private intermediaries could take advantage of. I suggest the creation of gatekeepers to avoid this risk and encourage further study on the impact of private intermediaries on the implementation of innovation.

\subsubsection{Authorship and publication status}

With the help of comments from my supervisor and other colleagues, I am the sole author of Paper 4.

This paper was presented at the 2013 ETH PhD Academy on Sustainability and Technology, which took place in Zurich in June 2013, and at the $13^{\text {th }}$ Colloquium of the European Group for Organizational Studies (EGOS) in July 2013 in Montréal. I intend to publish this paper in a journal on innovation studies. 


\section{Main findings}

The aim of this thesis is to better understand the new entrants within renewable electricity production by studying their characteristics, their motives and driving forces, and their challenges. The following section provides the answers to the research questions presented in Chapter 2.

\subsection{Who are the new entrants?}

This section provides a better understanding of the new entrants within renewable electricity production, with a focus on their share of new renewable electricity production in Sweden, their characteristics, and their differences.

\subsubsection{Their share within renewable electricity production}

Analysis of the data on Tradable Green Certificates (Paper 1) determined that the group of new entrants owned the majority of the new renewable electricity plants and of the capacity installed in Sweden in July 2012 (Figure 3). In contrast to what has been assumed in much of the previous energy policy literature (e.g. Awerbuch 2003, Awerbuch 2006, Pettersson and Söderholm 2009, Söderholm and Klaassen 2007), the majority of the organizations and individuals that invested in renewable electricity in Sweden over the past decade are not energy-planners or incumbent actors; instead, they are new entrants, either actors who are new on the production market (e.g., IPPs and project developers) or actors who have little or no experience or knowledge of the activity (e.g., farmers and diversifying companies). 


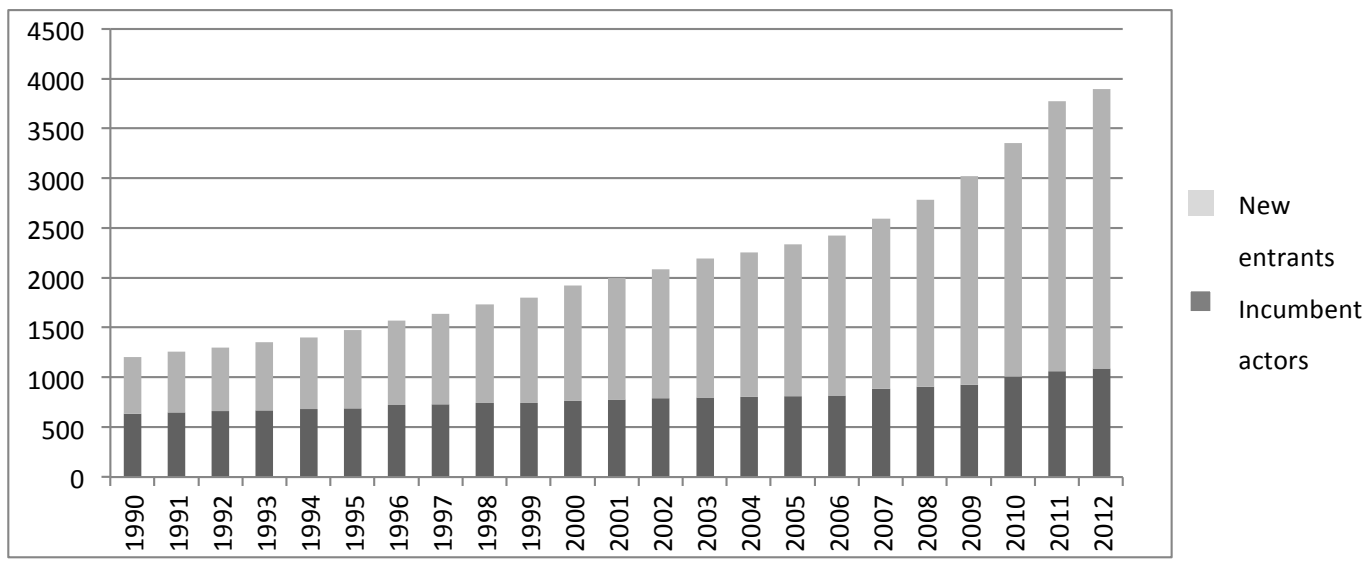

Figure 3. Accumulated number of renewable electricity plants per year of installation: new entrants vs. incumbent actors (Bergek et al. 2013).

\subsubsection{Their characteristics}

The categorization of renewable electricity producers made in Paper 1 stresses that new entrants within renewable electricity production are a very diverse group.

As suggested in the previous literature underlining the diversity of renewable electricity investors (e.g. Langniss 1996), and as shown in the results of the analysis of the Tradable Green Certificate database, their main activity varies. Only one category of new entrants, i.e., the independent power producers (IPPs), is specialized in renewable electricity production. All of the other new entrants have another main activity that they diversified by entering renewable electricity production.

Also, as previously noted (Dinica 2011, Wüstenhagen and Menichetti 2012), new entrants differ with regard to size and ownership structure. Data showed that some are public organizations (e.g., municipalities and municipal non-energy companies), familyowned businesses (e.g., some farming businesses or other diversifying companies), corporations owned by shareholders, and associations owned by their members. In terms of size (i.e., the number of employees and turnover), the new entrants can be very large (e.g., associations from 100 members to 51,000 members) or very small (e.g., diversifying companies or farmers with 1 or 2 owners).

In addition to the structural characteristics suggested by previous literature on new entrants and by the findings of Paper 1, the results of Papers 3 and 4 showed that new 40 
entrants have different access to resources for the implementation of projects and, in particular, different access to financial resources, knowledge, and natural resources. In contrast to previous literature, the data presented in Papers 3 and 4 suggest that this access to resources is not directly linked to structural characteristics; rather, access varies between actors within the same main activity and the same size and ownership structure.

One might assume that large companies have better access to financial resources and thus, are able to finance the investment in renewable electricity production with revenues from other business areas, whereas other types of organizations, such as farmers or associations, would have more difficulty gathering financial resources (cf., e.g., Bolinger et al. 2009). However, the large associations (i.e., more than 50,000 members) that were interviewed in this study had such access to financial resources that they were even able to build new staff structures to exploit the new activity. Likewise, the land and properties owned by some farmers made it possible for them to take out mortgages and receive loans from banks. This observation is worth noting, in light of the fact that the size of the investments was comparable among the new entrants (i.e., considering their yearly turnover). For instance, one of the farmers interviewed mentioned that his investment in wind power was equivalent to one year of his farm turnover, which is comparable with the investments made by some large diversifying companies (e.g., 2.25-million-euro investment in comparison with a 2-million-euro turnover for one diversifying company).

The same logic can be assumed for the access to knowledge and experience. Indeed, as explained in previous literature described in Paper 4 (e.g. Cohen and Levinthal 1990), it can be assumed that companies (such as engineering companies or papermanufacturers) who are familiar with complex technological processes or have a tradition of using innovations have more knowledge and skills than actors with no previous contact with the energy or technology sectors. However, as shown in Papers 2 and 3, many types of new entrants had personal interests in the technology and actually were more knowledgeable than high-technological companies. Likewise, according to the analysis presented in Paper 4, different types of skills and experiences were found across new entrant categories: some had experience in institutional processes (e.g., municipalities), others had experience in entering new business areas (e.g., diversifying 
companies), and some had experience in designing investments (e.g., project developers).

Access to natural resources is a characteristic that has not been considered in previous literature. As shown in Paper 3, it was not a determining factor of the structural characteristics of the new entrants, either. Some new entrants (e.g., companies within agriculture or forestry for wind power, or real estate companies for solar power) had direct access to natural resources within their own organization (or contact with other actors who did), while others had to find strategies to acquire these resources.

The networks, considered crucial for the implementation process in the institutional (e.g. Munir 2002) and innovation-adoption literature (e.g. MacVaugh and Schiavone 2010), also differed between the new entrants. For instance, farmers' networks were mainly composed of other farmers, farmers' trade associations, or suppliers of agricultural products and machines. In comparison, paper pulp or paper product companies had networks composed of forestry actors (i.e., the main suppliers of raw material), utilities (i.e., suppliers of electricity for these intensive electricity consumers), and large engineering companies (i.e., suppliers of the technologies needed for the production of paper), and they had well-established contacts with the municipal, regional, or even national institutions.

As suggested by the four theoretical dimensions used in this thesis (i.e., economic, entrepreneurship, institutional, and innovation-adoption, described in Section 2.2. and presented in Paper 1), the different prerequisites of new entrants affected their choices and implementation processes. For instance, the knowledge and experience of new entrants affected their perception of the innovation (e.g. Rogers 1962), helped them to recognize opportunities (e.g. Baron 2006), determined whether or not they perceived the investment as risky (e.g. Bhattacharya and Kojima 2012), and influenced their strategies for dealing with uncertainty when making decisions (e.g. Zimmerman and Zeitz 2002). 


\subsection{New entrants' motives and driving forces}

\subsubsection{Motives}

As suggested in some emerging energy policy literature (Masini and Menichetti 2012, Masini and Menichetti 2013), the results of Papers 2 and 3 indicate that the motives and driving forces of new entrants differ. In fact, the new entrants that we interviewed often had several motives for entering into renewable electricity production. Most of them had one primary motive and one or two secondary motives.

For some of the new entrants, the primary motive was, indeed, as suggested in previous energy policy literature (review in Chapter 2, Section 2.1.1.), the potential economic value of starting renewable electricity production. This was apparent from the way they described their decision and implementation processes. For instance, they described their evaluation of several investment options and their choice of the most valuable investment alternative at the time, considering the risks (i.e., uncertainties) and potential production profits. The decision to invest relied on detailed investment simulations based on the potential production and the different costs associated with the development of the project (e.g., prediction of the time needed for the permit processing). They also made a thorough technical investigation before choosing their technology supplier and equipment.

Surprisingly, however, for most of the new entrants, economic value was not the primary motive for deciding to produce renewable electricity. This was observed in the interviews, when new entrants mentioned economic considerations as one of several motives, but it was clear that their investment criteria and implementation processes were not in line with profit-maximization logic. For instance, some entrants decided to pay back their loans faster than required by the bank in order to avoid having debts, others did not make an investment appraisal because they trusted that the investment would be profitable, and other entrants were not aware that their plants were part of the tradable green certificate system. As suggested by Wüstenhagen and Menichetti (2012), this behavior contradicts the economic dimension adopted in the previous energy policy literature, which assumes that renewable electricity producers act according to economic models of full rationality. The main non-economic motives were sustainability, interest in the technology, and problems that needed solving. 
Sustainability motives have been associated mostly with environmental values in previous literature (such as the social entrepreneurship literature (Hockerts and Wüstenhagen 2010) or the institutional literature (e.g. Miller 2000)). However, the results of our analysis (Papers 2 and 3) show that a majority of those new entrants who had a sustainability motive were instead driven by resource optimization. They often held this sustainability motive in combination with an economic motive. They realized that they had access to a valuable resource and did not want to miss the opportunity to use it. For them, not exploiting this resource would have created a personal shortfall, i.e., missing the chance to freely exploit natural resources. These specific new entrants explained that the renewable electricity technology was chosen based on the resource that they wanted to optimize.

In the interviews, it became clear that the realization of their natural resource's value came from their network, often in the form of another person or organization that had access to a similar resource and found a way to exploit it. This confirms the institutional and the innovation-adoption dimensions (described in Sections 2.2.1. and 2.2.3. and presented in Papers 2 and 4), which underline the role of networks in the decision to adopt an innovation. It also confirms the entrepreneurship dimension, which explains why some individuals and organizations see the value or opportunity because of the information that is available to them, for instance, through their network.

Finally, the analysis of the interviews showed that the new entrants striving for resource optimization would not have started producing electricity if it had required them to buy the resource from someone else. However, the prospect of making even a small profit reinforced their primary motive.

The few new entrants who wanted to produce renewable electricity in order to play a role in a system change were actively involved in the energy debate (e.g., against nuclear power) and/or had a sustainable lifestyle. They had no economic motive and would have entered renewable electricity production even if it had resulted in a small net cost for them.

As suggested in the entrepreneurship dimension (Section 2.2.2.), which claims that some entrepreneurs are driven to exploit opportunities by their personal interests (e.g. Sigrist 
1999), some of the interviewed new entrants joined the renewable electricity market primarily because of their interest in the technology. For them, this meant fulfilling a dream or making a commitment to a technology that they had been following for a long period of time, for example, as a hobby, in fairs, through interest groups, or through specialized literature.

These new entrants were among the first ones to enter the market, at a time when the economic incentives were few and the technology was immature. In contrast to the assumptions of the economic dimension (Section 2.1.1.), economic motives were not their primary motive, even if they claimed to have always had a strong belief in the future profitability of the production. They did not conduct any investment appraisals and they tended not to consider their own time spent working on the development of the project as a cost-even when they built the whole plant on their own.

Finally, some of the interviewed new entrants had a problem to solve and saw renewable electricity production as (part of) the solution to that problem. In several cases, problems were due to a change in the new entrants' business environment, such as a regulatory change, a contract with a client or a supplier coming to an end, or negative media attention related to one of the organization's activities. In other cases, problems were caused by factors internal to the organization, such as an overflow of raw material or a change in leadership. They made the decision because it was a way to solve their problems, and it was an economically sound option (compared to other options).

In a sense, these actors had an economic motive, but it was secondary to the problemsolving motive. The primary motive of these actors was to react to a problem, rather than to actively pursue profiting from an opportunity (for instance, taking advantage of economic incentives). In the following section, we will further discuss the drivers and pressures that new entrants responded to when investing in renewable electricity.

\subsubsection{Drivers and pressures}

In Paper 2, an institutional perspective was used to study new entrants' decisions to start producing electricity and their methods of implementing that decision. Analysis of the interviews showed evidence that some drivers and pressures influenced the new entrants. Whether they were driven or pressured depended on whether they were 
proactive (and considered the force as an opportunity), or whether they were passive (and considered the force as a burden).

\subsubsection{The need of legitimacy}

As suggested by the institutional dimension presented in Section 2.2.1., new entrants motivated by sustainability, interest in the technology, or (in some cases) the need to solve a problem were driven by a need of legitimacy. For instance, the new entrants who started producing renewable electricity to contribute to a system change were influenced by environmental values existing in their network. They described forming their decision because "there was no other option" and because "this was the right thing to do" for the environment and to oppose nuclear power and other types of polluting technologies used for power generation. In other words, they were pressured by these values, yet motivated to use their decision to pressure others.

The new entrants who were motivated by resource optimization were also heavily influenced by the norms and values within their networks. For instance, one new entrant, who had access to a water stream, was repeatedly told by his customers and neighbors that it was "senseless" to let the water flow by without making the best of it. Likewise, several of the farmers that we interviewed explained that, among farmers, it is "natural" to make the best use possible of the resources available, and that farmers always look for new ways to exploit natural resources.

New entrants motivated by their interest in technology were also part of networks with similar interests. They described the great "honor" of making a machine worked by their own hands and the satisfaction of producing valuable electricity. Moreover, the fact that the technology diffused and became profitable over time increased their legitimacy (and their satisfaction).

Finally, for some of the new entrants motivated by a problem to solve, the problem was in fact a legitimacy issue. For instance, they may have received negative media attention (e.g., because of lack of environmental considerations) and decided to invest in renewable electricity production as a way to regain their legitimacy in the eyes of their shareholders and of society in general. 


\subsubsection{Policies and regulations}

Results of Paper 2 also show that some members of the new entrant group were driven or pressured to invest by institutional instruments (i.e., economic incentives or regulations). Most of the actors with a primary economic motive were triggered by economic incentives created by policies (i.e., in this case, the tradable green certificate system). They evaluated different investment alternatives, seeking the most profitable one, and the economic incentive made the difference between renewable electricity production and other options.

In contrast, some new entrants were pressured rather than driven by institutional factors such as regulations. As mentioned above, for some new entrants, changes in the regulatory environment created a problem that they solved by producing electricity. In that sense, the regulatory pressures led them to invest.

Regarding the analysis of new entrants' responses to internal driving forces and external pressures, we noticed a strong link between their motives and the drivers or pressures that they responded to. The influence of their networks and their norms and values were the drivers of a large number of actors. Economic incentives also had a positive impact on the decision of many actors, but for most of them, other triggers were more influential.

\subsection{New entrants' decision implementation: challenges and strategies}

Despite strong motives and (sometimes) strong responses to drivers and pressures, we discovered that the implementation of the decision to start producing renewable electricity production was punctuated by a number of challenges.

As explained in the theoretical framework of this thesis (Section 2), one characteristic that all new entrants have in common is that they are new at producing renewable electricity and new to the energy industry in general. They all decided to adopt a technology (i.e., one or several of the renewable electricity production technologies) that was new to them and relatively new to the market. In Paper 4, new entrants were, therefore, studied from an innovation-adoption perspective, and were regarded as innovation-adopters. 
As reviewed in Paper 4, previous innovation-adoption literature has suggested some potential challenges that can impact innovation-adopters during the implementation of the adoption (e.g. Linton 2002). Among the challenges mentioned, access to knowledge and training (e.g. Klein and Sorra 1996), internal negative attitudes toward the innovation (e.g. Leonard-Barton and Deschamps 1988), access to information (Rogers 1962), and access to financial resources (Klein et al. 2001) are the main ones that have been identified during the implementation process. Results of our interviews partially confirm these challenges and even highlight a number of new challenges that may be specific to the renewable electricity production context. In the following sections, the four main challenges described by different categories of new entrants and the corresponding strategies used by them will be discussed.

\subsubsection{Challenges met by new entrants}

Based on the new entrants' description of their implementation processes and their difficulties associated with them, four main perceived challenges emerged, without clear predominance among new entrants with the same size, main activity, or ownership: lack of resources, lack of knowledge and experience, administrative challenges, and the local context of the implementation.

\subsubsection{Lack of resources}

Despite emphatic claims by previous literature on innovation-adoption, lack of resources was not one of the biggest challenges for the new entrants whom we interviewed. A few of them did mention the challenge of obtaining access to financial resources (i.e., investment capital and loan) and/or natural resources (i.e., places to build the renewable electricity plant or biomass to be used as fuel), but these entrants were in the minority. Examples of implementations where financial resources became a challenge included e.g., new entrants who had planned their projects assuming that they would get a bank loan that, at the end, did not materialize, and new entrants whose partners (and co-investors) withdrew from the project at a late stage. These new entrants had to make changes in their initial strategy, either by gathering financial resources in another way or by reducing the cost of the project. This type of challenge was not associated with any particular category (or structural characteristic) of new entrants, although it could have been assumed that small organizations or certain types 
of businesses (e.g., farming businesses) would have been overrepresented among new entrants having difficulties gathering financial resources. Of note, however, is the fact that no association or municipal company claimed to have faced these challenges. On the contrary, municipalities mentioned that they were able to contract loans with a low interest, and associations mentioned that they were able to gather members quickly (and, therefore, sell the shares of the projects).

A challenge that has not been addressed in previous literature, but that emerged in this study, is the access to natural resources. This occurred in the implementation of a few projects where new entrants had relied on the access to a natural resource, but the owner of that resource withdrew his/her offer. Some project developers also mentioned cases where they had been actively seeking new places to develop wind power projects, but the landowners had already signed leases with other companies. These are exceptions, however, since most project developers stated that they were overwhelmed with landowners offering the possibility of renting land for the development of wind power projects.

\subsubsection{Lack of knowledge and experience}

In comparison with the financial and natural resource challenges, the challenges related to lack of knowledge and/or experience were predominant among all types of new entrants.

Because of their lack of knowledge of the technology and the project development process, many new entrants explained that they had felt unsure of the choices available to them during the implementation process. In particular, they had been uncertain about what type of machine to buy in order to make the best use of the innovation. Because of that, they frequently made choices that seemed sound to them, but were often based on information from their networks, thereby not considering the special context of their implementation. This mechanism confirms the influence of networks underlined in the institutional dimension (e.g. Scott 1995) and presented in Paper 2.

The lack of knowledge and experience of the technology also created uncertainties with regard to the financial security of the project. New entrants often had to rely on investment appraisals made for them by others, e.g., accountants, suppliers, or project 
developers, which made them feel like they lacked control over the project. This often led them to make conservative (i.e., safe) choices: for instance, excluding policy support measures from the appraisal, assuming low electricity prices and production, or assuming a lower lifetime of the machine than recommended by the suppliers. This is in line with the economic literature regarding investors' strategies to handle risks (e.g. Donovan and Nuñez 2012). This also correlates to the policy literature with regard to the consequence of insecurity on investments (e.g. Söderholm et al. 2007).

In line with the institutional dimension, which underlined the power associated with legitimacy (e.g. DiMaggio and Powell 1983), because of their lack of experience, some new entrants lacked legitimacy, which resulted in a lack of market contacts (for instance, with suppliers) or the inability to obtain what they characterized as a fair offer from technology and infrastructure suppliers. After the implementation of the projects, some new entrants also struggled to find a utility willing to buy their produced electricity at a respectable price.

\subsubsection{Administrative challenges}

One challenge, which has not been addressed in the innovation-adoption literature, but which is addressed in literature about renewable electricity projects (Söderholm et al. 2007, Ek 2005, Khan 2003), is the complexity of the administrative process of the implementation. Indeed, the permit application process was described as long and complicated and the interviewed new entrants felt that they had no real control over it.

This challenge was prevalent among the majority of the new entrants. For instance, many of them were refused building permits at a municipal level and had to appeal the decision to a higher source. This led to frustration and, sometimes, forced them to change the location of the plant.

\subsubsection{The local context of the implementation}

In close relation with the previous challenge, and described in previous literature about renewable electricity production (Khan 2003, Toke 2005a), many new entrants faced challenges associated with the local context of the implementation. In some contexts, the 
local environment was described as particularly hostile to renewable electricity projects.

This had a direct impact on the implementation of projects, as local opposition led to longer and more complex permit applications. In some cases, the process was blocked not by the local inhabitants, but by interest groups, such as the Army or various bird protection associations.

The local context sometimes created physical challenges as well. For instance, some sites are situated in areas that are far from the grid, which therefore, resulted in challenges connecting the renewable electricity plant. This was the case of geographical areas that were particularly challenging because of extreme weather or natural circumstances (e.g., forests and mountains). This type of challenge was, however, only faced by a few of the new entrants. Indeed, only IPPs or project developers chose to implement projects in that type of context, because they needed to find places and circumstances that allowed the construction of large wind parks.

\subsubsection{Strategies to cope with the challenges}

The fact that only the new entrants whose implementations endured until the end were studied (i.e., not the actors who were forced to abandon their projects or the actors who did not want to invest in renewable electricity production at all) provided the opportunity to study the way in which they handled the challenges. In the following section, which is based on the analysis of the interviews and theoretical dimension of Paper 4, the strategies chosen by new entrants are presented, as well as the pros and cons of the different strategies.

\subsubsection{Learning}

Some of the new entrants who were confronted with challenges relating to a lack of knowledge and experience chose an investment strategy: they invested their time and money to learn and acquire the competencies that were missing. They delayed the project (sometimes, even for a few years) to devote time to learning about the technology and creating the contacts that they needed to implement their own projects. 
They participated in trade fairs, visited other plants, and read specialized literature about the technology that particularly interested them.

This strategy presented both advantages and drawbacks. The main advantage was that the new entrants kept their independence; they did not have to rely on others in making their implementation decisions, and they had a clear justification for each choice. Another benefit was that they were able to support others in their networks in implementing projects at a later date. The strategy, thus, had a diffusion effect, and most of the new entrants who followed that strategy decided (or planned) to develop new renewable electricity projects for themselves or for others in the future. Finally, the implementation cost was often lower than that for other new entrants. The main drawback, however, was that the implementation of the project, from the decision to start producing renewable electricity to the formation of an operational plant, took a long time.

\subsubsection{Networking}

As we mentioned, and as previous innovation-adoption literature (e.g. Chesbrough 2006) has discussed, many of the new entrants used their networks to cope with challenges; this was especially true with regard to those confronted with a lack of resources and a lack of knowledge and experiences. Networks helped, for instance, to gain new entrants access to complementary resources. Some new entrants lacking knowledge and experience also heavily relied on their networks to make implementation choices, whereas some simply copied the implementation choices made by others. Many entrants received information from their networks about, for example, good or bad experiences with suppliers, new technology believed to be adapted to the new entrants' needs, and methods to obtain financial support or better interest rates.

The main advantage of the networking strategy is the fact that it allowed a number of new entrants to start producing renewable electricity, despite clear obstacles. Some of them would not have been able to do so without that assistance. In fact, the results of our interviews lead one to question whether some of these new entrants would even have thought about starting a renewable electricity production if they had not been convinced by their networks. 
The main drawback of this strategy is related to the quality of the implementation. Indeed, the new entrants that, for instance, copied the implementation of their networks had no guarantee that the choices would be adapted to their own context (e.g., geographical condition or the current external condition, such as the availability of better production equipment). Moreover, aspects such as satisfaction or dissatisfaction were linked to the perceptions of these network actors and not particularly to concrete factors.

\subsubsection{Creating partnerships}

As suggested by the resource combination process described in the entrepreneurship dimension (e.g. Shane and Venkataraman 2000), some new entrants who faced challenges related to lack of resources, lack of knowledge and experience, or the local context of the project carried out their implementation by creating partnerships. In many cases, renewable electricity production projects were developed in partnerships between new entrants with financial or natural resources and new entrants with market or technological knowledge. Likewise, many new entrants chose to involve their neighbors or the inhabitants living close to the intended location of the plant in order to avoid the local opposition that could have led to a denied or detailed construction permit.

There were mainly advantages to creating partnerships as a strategy to cope with challenges. These new entrants were able to combine their resources to make the project possible, to improve the quality of the implementation (e.g., a larger number of choices to choose from and a higher level of expertise), and to shorten the process (especially with regard to the permit application). One disadvantage is the lack of independence for the new entrants, since compromises were necessary to satisfy the partners.

\subsubsection{Hiring consultants}

As presented in Paper 4, hiring the services of experts (i.e., consultants) is the strategy that some actors who lacked knowledge and experience chose to implement their projects. This is in accordance with the innovation literature, which has underlined the role that can be played by innovation intermediaries to handle a lack of knowledge and 
market integration (e.g. Chesbrough 2006, Hargadon and Sutton 1997). The new entrants who hired consultants felt confident enough to handle the rest of the implementation, but were unable to perform some expert tasks such as wind estimations, photomontages, or permit applications.

The main advantages of this strategy were that new entrants did not lose time by struggling with some of the difficult tasks on their own, and that they avoided the risk of reducing the quality of their implementation, such as the quality of the permit application or the financial appraisal, due to a lack of expertise. The main drawback, however, was the high cost of the implementation, as hiring multiple experts could be very expensive.

\subsubsection{Delegating the whole implementation process}

Finally, some new entrants chose to delegate the whole implementation process to private intermediaries. Here, unlike the previous strategy where consultants were hired for specific tasks within the implementation, a project developer was appointed to manage and coordinate the whole implementation process. This includes acquiring access to natural resources, choosing the suppliers, applying for the permit, handling the contacts with the institutions in charge of the permits, contacting the grid owner, and managing the local opposition. This strategy was adopted by a diverse group of new entrants, such as actors lacking knowledge and experience only or actors with business experience who are confronted with numerous challenges. Despite the attention that intermediaries have received in previous innovation literature, this particular strategy of delegating the whole innovation implementation to a third party has never before been described.

In our interviews, it appeared that the main advantage of this strategy was in its efficiency. The projects were driven by project developers who were fully integrated in the market and had direct contacts (and sometimes special benefits or offers) with suppliers, legitimacy in the eyes of local and regional organizations (i.e., municipalities) and experience in handling local opposition. This increased the quality of the implementation, since knowledgeable and experienced people developed the projects. 
The main drawback, however, was the fact that the new entrants lost control over their own project implementation. Indeed, because of their authority and the new entrants' limited knowledge or lack of participation, project developers were more or less free to make choices that were not always in the best interest of their clients. For instance, in some cases, they had informal partnerships with equipment suppliers; these partnerships could have created a bias in their implementation. 


\section{Policy implications: what can be learned from these findings?}

As has been demonstrated in this thesis and in all four papers, it is clear that the new entrants within renewable electricity production are not a homogeneous group as earlier assumed by policy-makers. Instead, they constitute a diverse group with different characteristics, motives, responses to drivers and pressures, challenges, and strategies to solve those challenges.

Although the majority of the current investments in renewable electricity production can be attributed to new entrants, this study revealed the fact that many of these new entrants lack knowledge and experience in developing renewable electricity projects and that this is one of the main challenges associated with their entry process. From the study of the new entrants' strategies to cope with challenges, it became clear that new entrants chose different ways to handle this crucial lack of knowledge and experience. For instance, some chose to invest time and money to learn, which delayed the implementation, and others chose to create partnerships with more knowledgeable and experienced actors, whereas those who were lacking only some of the knowledge hired experts to obtain specific help. However, some new entrants chose strategies that may pose a risk for the quality of the implementation: relying on their networks and delegating the whole implementation to private intermediaries. This may have an impact on the overall quality of projects developed by new entrants, which should be addressed by policy-makers.

A second aspect that should be acknowledged and managed by policy-makers is the fact that only one part of the new entrant group harbors economic motives and is driven or pressured by current economic policy incentives. If such incentives are distributed to a large number of new entrants who would have joined renewable electricity production even without them, then the policy system cannot be considered cost-efficient, despite discussions in the policy debate (e.g. Butler and Neuhoff 2008). Instead, other drivers and pressures have been identified as more important for new entrants, e.g., the need of legitimacy and, in particular, the impact of network pressures, which may be considered in future policies. 
This leaves policy-makers with several options to improve the current policy system. One way of dealing with the negative impact of the new entrants' implementation would be to support some or all of them (and potentially attract more) in order to improve the quality of their implementation processes. Another option would be to leave the renewable electricity production market to incumbent actors, thereby minimizing the entry of unknowledgeable and inexperienced actors. In the following sections, I will provide some suggestions on how to proceed with these different scenarios.

\subsection{Scenario 1: New policies to attract and to support new entrants}

If policy-makers want to attract additional investments within renewable electricity production, mechanisms to attract additional new entrants can be created. The study of the existing new entrants in Sweden showed that, in addition to the new entrants with economic motives, who were driven by economic incentives, many new entrants joined the renewable electricity production due to a need for legitimacy. For these new entrants, the role of their network was crucial; this role could be exploited to attract additional new entrants.

Efforts can be made, for instance, to diffuse information about the possibility to invest in renewable electricity production through trade associations (e.g., within farmer trade associations) or interest groups (e.g., organizations interested in solar or wind power). Forums can be created, where existing producers could exchange experiences and share information with potential new entrants and where potential new entrants with access to different types of resources (e.g., natural resources, financial resources, or knowledge and experience) and motives (e.g., interest in the technology and resource optimization) could meet.

Another way to attract more new entrants is to develop regulations pressuring some potential new entrants to invest. Among the existing new entrants, several joined renewable electricity production in order to solve such regulation "problems."

As discussed above, attracting additional new entrants also has some drawbacks, which should be addressed. First, most of them lack knowledge and experience. Before attracting more of them, therefore, policy-makers must provide them with support to develop their projects in an efficient and effective way. One way to do that could be to 
provide them with the opportunity to learn, for instance, through development programs or through information (e.g., guidelines or checklists). Another way could be to provide them with project development guidelines or with support from public (or, under some conditions, private) intermediaries.

\subsection{Scenario 2: New policies to secure the level and the quality of investments in renewable electricity production}

If policy-makers consider that new entrants, because of their lack of knowledge and experience, pose a risk for the development of new renewable electricity projects, they could develop new policies to limit the entry of additional new entrants or, at least, prevent the development of low-efficiency projects.

One way to do that could be to increase the complexity of the entry process by, for example, adding gate-keeping criteria such as efficiency limits or project-size limits (therefore, requiring access to large financial resources).

Another way to prevent the development of low-efficiency projects could be to encourage new entrants to use intermediaries to develop their projects by, for instance, encouraging the creation of economic associations run by intermediaries, sponsoring the use of intermediaries, or developing public intermediary functions at the municipal or regional levels.

This scenario also has some drawbacks, however, that should be addressed. First, limiting the entry of new actors also means limiting the majority of the current investments in renewable electricity. This is not a problem if policy-makers estimate that targets in terms of renewable electricity have been reached. However, if the current renewable electricity production still needs to be increased, investments will have to be made by incumbent actors. Until now, they have not taken the lead in investing in this type of project (Figure 3). Therefore, policy-makers must further encourage them by supporting their investments, for example, or they must pressure incumbents to act, by imposing regulations or by including clear investment requirements in their instructions for state-owned incumbents.

Second, adding to the current complexity of project development also means that the number of projects being developed may decrease. Solutions may, therefore, be needed 
to find criteria that encourage high-quality projects, in addition to the criteria that prevent low-quality projects. A way to do so may be to prioritize large projects or projects developed in areas that have been identified as particularly efficient.

Finally, given the potential risks of private intermediaries identified in this study and emphasized in previous literature, measures should be taken to cope with the lack of control of the actors (i.e., new entrants and incumbents) who use their services. Efficiency criteria may be a way to achieve this and the development of stronger public intermediaries may be an alternative to private intermediaries.

\subsection{Summary}

I presented two potential scenarios that could be considered by policy-makers, but other scenarios are possible; one might even be a combination of the two that have been presented here. The most important aspect to consider is the acknowledgment of new entrants and the determination of whether they should be considered an opportunity or a risk for the quality of the system transition. In fact, their presence on the market could easily be optimized by a number of simple and inexpensive measures, such as forum creations and the dissemination of information. Meanwhile, the risk of low-efficiency project developments can apply for both incumbents and new entrants, even if the lack of knowledge and experience of the latter increases that risk. A simple way to avoid this type of problem for all types of actors is the creation of quality criteria. 


\section{Concluding remarks}

\subsection{Conclusion}

To conclude, it is now clear that the decision to question the assumptions that have been made in previous energy policy on the producers of renewable electricity was a valid one. Results from the study show that the majority of the investments in renewable electricity production made in Sweden in the last 10-15 years can be attributed to new types of actors, that is, a group of actors with no or little prior experience within electricity production. This means that there is a clear need for policy-makers to reconsider the impact of current policies and to think about different scenarios for the future of renewable electricity production.

The answer to each research question in the thesis highlights the fact that new entrants share different traits, motives, plans, actions, responses, and coping mechanisms. This heterogeneity has a number of implications. First, renewable electricity production does not attract only one particular type of actor, as sometimes assumed in previous literature or among policy-makers, but a very diverse group of actors with different profiles, such as access to resources, experience, and strategies. This means that the additional investments in renewable electricity production, which are much needed for a system change, can be made by any type of actor, not only incumbent actors.

Second, the different motives of new entrants indicate that profit is not the only reason why they start producing renewable electricity. Even if economic factors are relevant, they are most often only a secondary motive. New motives were identified, which, to a limited extent, have been highlighted in previous energy policy literature: the sustainability motive, an interest in the technology, and a problem to solve. An interesting aspect regarding these motives is that new entrants with similar structural characteristics or prerequisites do not have similar motives. We found all types of structural characteristics and prerequisites among new entrants with similar motives.

Third, new entrants responded to different drivers and pressures, e.g., economic incentives, regulations, or a need of legitimacy. Some new entrants were proactively driven and saw the renewable electricity production as an opportunity, whereas others were more passive and felt pressured to invest. Again, there was no direct link between 
new entrants' characteristics and the forces that drove or pressured them to start producing renewable electricity. However, there was a clear relationship between their motives and the driver or pressure they responded to when making the decision to invest. Therefore, the only new entrants who were clearly responsive to policy were those with a primary economic motive, who were driven by economic incentives, and those for whom regulation created a problem to solve. Likewise, the need of legitimacy drove the new entrants with an interest in the technology or with the wish to contribute to system change, whereas it pressured those investing for resource optimization motives. The need of legitimacy was the main driver or pressure among the whole group of new entrants, although it has not been discussed in previous energy literature. Another interesting dimension is that the same influence (e.g., the need of legitimacy) can be perceived as a burden for some and as an opportunity for others.

Fourth, the study of challenges met by new entrants showed that they faced four main difficulties during the implementation of the renewable electricity projects: lack of resources (i.e., financial and natural), lack of knowledge and experience, challenges related to the administration process (i.e., permit applications) and challenges related to the local context of the project. The fact that the lack of resources was a minor challenge among all types of new entrants came as a surprise, given that some of them had limited access to financial resources and that previous literature had described it as a main barrier. The challenges related to the administrative process of the implementation and to the local context were in accordance with what has previously been written in the literature on renewable electricity. The key challenge was identified as a lack of knowledge and experience. This was predictable, since new entrants had just adopted the technology, but it has not received the attention that it deserves in the previous literature on energy policy.

Finally, the study of the strategies chosen by new entrants to cope with the challenges that they met during the implementation process again show how diverse (but inventive) they are when acquiring and combining the missing resources. In this process, two main groups played a great role: networks and project developers/consultants. All strategies chosen have their pros and cons, but they show that, even without the renewable electricity producer profile imagined by policy- 
makers, new entrants were able to successfully plan and implement their projects, at least on the level of the individual project.

Policy-makers must acknowledge the new entrants on the production market and decide whether they should be encouraged or discouraged. On the one hand, if new entrants are wanted, policies targeting them should be developed to help them cope with their lack of knowledge and experience. On the other hand, if policy-makers consider that they represent too much of a risk for the efficiency of the energy system, then policies limiting their participation should be created. However, since limiting their access would also mean leaving the entire responsibility of producing renewable electricity to incumbent actors, who have not shown the same level of interest in this activity yet, the impact of these measures should be evaluated cautiously before actions are taken to further encourage or force the incumbents to invest.

\subsection{Suggestions for further research}

The findings and the conclusions of this thesis are based on the study of a number of cases of new entrants of the renewable electricity production (37) within one contextual case (Sweden). As discussed in the methodology section of the thesis, this method (in particular, the choice of the main cases and the extensive number of subcases) was well adapted to the exploratory purpose of the study and to the complexity of the total population of new entrants. However, further research is still required to be able to guarantee the generalizability of these findings. Therefore, I suggest three main areas for further research of the new entrants within renewable electricity.

First, now that some propositions have been made regarding the motives, responses, and challenges of the new entrants, they should be tested on a larger sample of new entrants. Ideally, they should be tested on the whole population of new entrants in order to grasp the proportions with similar motives, similar responses to drivers and pressures, and similar challenges. A larger sample would also allow for testing the proposition that new entrants' motives are correlated with their responses to drivers and pressures (in particular, responses to economic incentives).

The reliability of the findings would also be increased if compared with other cases. Therefore, further research should compare Sweden with other countries, ideally with 
other geographical, economic, and policy contexts. In these additional cases, the share of new entrants, their characteristics, their motives, their responses to drivers and pressures, their challenges, and their strategies to cope with challenges should be studied and compared with the findings of this thesis.

The findings of this thesis have stressed the heterogeneity of new entrants and its implications for future policies. These implications have been drawn for the specific context of renewable electricity innovations, but may be relevant for other types of innovations, where the diffusion stage has not been reached yet. Similar studies should, therefore, be conducted in other diffusion contexts, for instance, with regard to other innovations or other industrial sectors. For example, further studies could consider the way farmers adopt agricultural innovations to increase their production, or the way the automobile manufacturing industry adopts innovations to increase the quality of their products. In these studies, the theoretical framework suggested in this thesis may be used in order to explore the actor perspective of the innovation diffusion.

Finally, the results of this thesis have brought some new insights to the process in which entrepreneurs break with their routines to exploit an opportunity, particularly with regard to the value (i.e., motive) that different actors may see in the opportunity. The previous literature on opportunity value and opportunity recognition assumes that the entrepreneurial value is strictly economic (e.g. Schumpeter 1934, Shane and Venkataraman 2000) or social (e.g. Dees 1998 , Dorado 2006). In this thesis, I have shown that opportunity values might be more complex than previously assumed, and I suggest that these values be further studied. 


\section{References}

Aldrich, H. E. \& Fiol, C. M. 1994. 'Fools Rush in? The Institutional Context of Industry Creation.' The Academy of Management Review, 19:4, 645-70.

Alvarez, S., A. \& Busenitz, L., W. 2001. 'The entrepreneurship of resource-based theory.' Journal of Management, 27:6, 755-75.

Ardichvili, A., Cardozo, R. \& Ray, S. 2003. 'A theory of entrepreneurial opportunity identification and development.' Journal of Business Venturing, 18:1, 105-23.

Ashford, N. A. 2002. 'Government and Environmental Innovation in Europe and North America.' American Behavioral Scientist, 45:9, 1417-34.

Awerbuch, S. 2003. 'Determining the real cost: Why renewable power is more costcompetitive than previously believed.' Renewable Energy World:March-April 2003.

Awerbuch, S. 2006. 'Portfolio-Based Electricity Generation Planning: Policy Implications For Renewables And Energy Security.' Mitigation and Adaptation Strategies for Global Change, 11:3, 693-710.

Baron, R. A. 2006. 'Opportunity Recognition as Pattern Recognition: How Entrepreneurs "Connect the Dots" to Identify New Business Opportunities.' The Academy of Management Journal, 20:1, 104-19.

Bergek, A., Mignon, I. \& Sundberg, G. 2013. 'Who invest in renewable electricity production? Empirical evidence and suggestions for further research.' Energy Policy:56, 568-81.

Bhattacharya, A. \& Kojima, S. 2012. 'Power sector investment risk and renewable energy: A Japanese case study using portfolio risk optimization method.' Energy Policy, 40, 69-80.

Birley, S. 1985. 'The role of networks in the entrepreneurial process.' Journal of Business Venturing, 1:1, 107-17.

Bode, S. \& Michaelowa, A. 2003. 'Avoiding perverse effects of baseline and investment additionality determination in the case of renewable energy projects.' Energy Policy, 31:6, 505-17.

Bolinger, M., Harper, J. \& Karcher, M. 2009. 'A review of wind project financing structures in the USA.' Wind Energy, 12:3, 295-309.

Brush, C. G., Greene, P. G. \& Hart, M. M. 2001. 'From initial idea to unique advantage: The entrepreneurial challenge of constructing a resource base.' Academy of Management Executive, 15:1, 64-78.

Butler, L. \& Neuhoff, K. 2008. 'Comparison of feed-in tariff, quota and auction mechanisms to support wind power development.' Renewable Energy, 33:8, 1854-67.

Carlson, A. 2002. 'On cost-effective technical measures to avoid environmental damages of regional energy systems.' International Journal of Energy Research, 26:12, 1103-15.

Carlsson, B. \& Stankiewicz, R. 1991. 'On the nature, function and composition of technological systems.' Journal of evolutionary economics, 1:2, 93-118.

Casson, M. C. 1982. The Entrepreneur: An Economic Theory. Oxford: Martin Robertson.

Chesbrough, H. 2006. Open Business Models: How toThrive in the New Innovation Landscape. Boston, MA.

Cohen, B. \& Winn, M. I. 2007. 'Market imperfections, opportunity and sustainable entrepreneurship.' Journal of Business Venturing, 22:1, 29-49.

Cohen, W. M. \& Levinthal, D. A. 1990. 'Absorptive Capacity: A New Perspective on Learning and Innovation.' Administrative Science Quarterly, 35:1, 128-52. 
Dees, J. 1998 'The meaning of social entrepreneurship'.

del Río, P. \& Gual, M. 2004. 'The promotion of green electricity in Europe: present and future.' European Environment, 14:4, 219-34.

Delmas, M. A. \& Montes-Sancho, M. J. 2011. 'U.S. state policies for renewable energy: Context and effectiveness.' Energy Policy, 39:5, 2273-88.

DiMaggio, P. J. \& Powell, W. W. 1983. 'The Iron Cage Revisited: Institutional Isomorphism and Collective Rationality in Organizational Fields.' American Sociological Review, 48:2, 147-60.

Dinica, V. 2006. 'Support systems for the diffusion of renewable energy technologiesan investor perspective.' Energy Policy, 34:4, 461-80.

Dinica, V. 2011. 'Renewable electricity production costs-A framework to assist policymakers' decisions on price support.' Energy Policy, 39:7, 4153-67.

Donovan, C. \& Nuñez, L. 2012. 'Figuring what's fair: The cost of equity capital for renewable energy in emerging markets.' Energy Policy, 40, 49-58.

Dorado, S. 2006. 'Social entrepreneurial ventures: different values so different process of creation, no?' Journal of Developmental Entrepreneurship, 11:4, 319-43.

Dorian, J. P., Franssen, H. T. \& Simbeck, D. R. 2006. 'Global challenges in energy.' Energy Policy, 34:15, 1984-91.

Eisenhardt, K. M. 1989. 'Building theories from case study research.' Academy of management review, 14:4, 532-50.

Eisenhardt, K. M. \& Bourgeois, L. J. 1988. 'Politics of strategic decision making in highvelocity environments: Toward a midrange theory.' Academy of management journal, 31:4, 737-70.

Eisenhardt, K. M. \& Graebner, M. E. 2007. 'Theory building from cases: opportunities and challenges.' Academy of management journal, 50:1, 25-32.

Eisner, E. W. \& Peshkin, A. 1990. Qualitative inquiry in education: The continuing debate. Teachers College Press New York.

Ek, K. 2005. 'Public and private attitudes towards "green" electricity: the case of Swedish wind power.' Energy Policy, 33:13, 1677-89.

Faúndez, P. 2008. 'Renewable energy in a market-based economy: How to estimate its potential and choose the right incentives.' Renewable Energy, 33:8, 1768-74.

Ferlie, E., Fitzgerald, L., Wood, M. \& Hawkins, C. 2005. 'The nonspread of innovations: the mediating role of professionals.' Academy of management journal, 48:1, 11734 .

Finon, D. \& Perez, Y. 2007. 'The social efficiency of instruments of promotion of renewable energies: A transaction-cost perspective.' Ecological Economics, 62:1, 77-92.

Fitzsimmons, J. R. \& Douglas, E. J. 2011. 'Interaction between feasibility and desirability in the formation of entrepreneurial intentions.' Journal of Business Venturing, 26:4, 431-40.

Fleten, S. E., Maribu, K. M. \& Wangensteen, I. 2007. 'Optimal investment strategies in decentralized renewable power generation under uncertainty.' Energy, 32:5, 80315.

Frey, G. W. \& Linke, D. M. 2002. 'Hydropower as a renewable and sustainable energy resource meeting global energy challenges in a reasonable way.' Energy Policy, 30:14, 1261-65.

Geels, F. W. 2002. 'Technological transitions as evolutionary reconfiguration processes: a multi-level perspective and a case-study.' Research policy, 31:8-9, 1257-74. 
Geels, F. W. 2004. 'From sectoral systems of innovation to socio-technical systems: Insights about dynamics and change from sociology and institutional theory.' Research policy, 33:6 897-920.

Geels, F. W. \& Schot, J. 2007. 'Typology of sociotechnical transition pathways.' Research policy, 36:3, 399-417.

Genus, A. \& Coles, A.-M. 2008. 'Rethinking the multi-level perspective of technological transitions.' Research policy, 37:9, 1436-45.

Gersick, C. J. 1988. 'Time and transition in work teams: Toward a new model of group development.' Academy of management journal, 31:1, 9-41.

Guth, W. D. \& Ginsberg, A. 1990. 'Guest Editors' Introduction: Corporate Entrepreneurship.' Strategic Management Journal, 11:ArticleType: misc / Issue Title: Special Issue: Corporate Entrepreneurship / Full publication date: Summer, 1990 / Copyright (C) 1990 John Wiley \& Sons, 5-15.

Haas, R., Resch, G., Panzer, C., Busch, S., Ragwitz, M. \& Held, A. 2011. 'Efficiency and effectiveness of promotion systems for electricity generation from renewable energy sources - Lessons from EU countries.' Energy, 36:4, 2186-93.

Hannan, M. T. \& Freeman, J. 1989. Organizational ecology. Cambridge, MA: Harvard University Press.

Hargadon, A. \& Sutton, R. I. 1997. 'Technology Brokering and Innovation in a Product Development Firm.' Administrative Science Quarterly, 42:4, 716-49.

Hitt, M. A., Ireland, R. D. \& Hoskisson, R. E. 1997. Strategic Management: Competitiveness \& Globalization, Concepts. St Paul, MN.: West Publishing Co.

Hockerts, K. \& Wüstenhagen, R. 2010. 'Greening Goliaths versus emerging Davids Theorizing about the role of incumbents and new entrants in sustainable entrepreneurship.' Journal of Business Venturing, 25:5, 481-92.

Hoffman, A. J. 1999. 'Institutional Evolution and Change: Environmentalism and the U.S. Chemical Industry.' The Academy of Management Journal, 42:4, 351-71.

Huang, Y.-H. \& Wu, J.-H. 2008. 'A portfolio risk analysis on electricity supply planning.' Energy Policy, 36:2, 627-41.

IEA 2013. 'Key World Energy Statistics 2012.' International Energy Agency.

IKEA 2013. 'People \& Planet Positive - IKEA Group Sustainability Strategy for 2020.'

Jacobsson, S. \& Bergek, A. 2004. 'Transforming the energy sector: the evolution of technological systems in renewable energy technology.' Industrial and corporate change, 13:5, 815-49.

Jacobsson, S., Bergek, A., Finon, D., Lauber, V., Mitchell, C., Toke, D. \& Verbruggen, A. 2009. 'EU renewable energy support policy: Faith or facts?' Energy Policy, 37:6, 2143-46.

Jacobsson, S. \& Johnson, A. 2000. 'The diffusion of renewable energy technology: an analytical framework and key issues for research.' Energy Policy, 28:9, 625-40.

Johnson, A. 2001. 'Functions in innovation system approaches.' Paper presented at Documento presentado a la Conferencia Nelson-Winter. Aalborg: Dannish Research Unit for Industrial Dynamics (DRUID).

Johnson, A. \& Jacobsson, S. 2001. 'Inducement and Blocking Mechanisms in the Development of a New Industry: The Case of Renewable Energy Technology in Sweden.' In E. E. Publishing (Ed.) Technology and the Market: Demand, Users and Innovation

Kahn, E. 1996. 'The production tax credit for wind turbine powerplants is an ineffective incentive.' Energy Policy, 24:5, 427-35. 
Kangas, H.-L., Lintunen, J., Pohjola, J., Hetemäki, L. \& Uusivuori, J. 2011. 'Investments into forest biorefineries under different price and policy structures.' Energy Economics, 33:6, 1165-76.

Khan, A. M. 1986. 'Entrepreneur characteristics and the prediction of new venture success.' Omega, 14:5, 365-72.

Khan, J. 2003. 'Wind power planning in three Swedish municipalities.' Journal of Environmental Planning and Management, 46:4, 563-81.

Kirzner, I. 1973. Competition and Entrepreneurship. Chicago: University of Chicago Press.

Kirzner, I. M. 1997. 'Entrepreneurial Discovery and the Competitive Market Process: An Austrian Approach.' Journal of Economic Literature, 35:1, 60-85.

Klein, K. J., Conn, A. B. \& Sorra, J. S. 2001. 'Implementing computerized technology: An organizational analysis.' Journal of Applied Psychology, 86:5, 811-24.

Klein, K. J. \& Sorra, J. S. 1996. 'The Challenge of Innovation Implementation.' The Academy of Management Review, 21:4, 1055-80.

Langniss, 0. 1996. 'Instruments to foster renewable energy investments in Europe a survey under the financial point of view.' Renewable Energy, 9:1-4, 1112-15.

Leonard-Barton, D. \& Deschamps, I. 1988. 'Managerial Influence in the Implementation of New Technology.' Management Science, 34:10, 1252-65.

Linton, J. D. 2002. 'Implementation research: state of the art and future directions.' Technovation, 22:2, 65-79.

Lucas, H. C., Jr. 1978. 'Empirical Evidence for a Descriptive Model of Implementation.' MIS Quarterly, 2:2, 27-42.

MacVaugh, J. \& Schiavone, F. 2010. 'Limits to the diffusion of innovation: A literature review and integrative model.' European Journal of Innovation Management, 13:2, 197-221.

Madlener, R., Kumbaroğlu, G. \& Ediger, V. Ş. 2005. 'Modeling technology adoption as an irreversible investment under uncertainty: the case of the Turkish electricity supply industry.' Energy Economics, 27:1, 139-63.

Masini, A. \& Menichetti, E. 2012. 'The impact of behavioural factors in the renewable energy investment decision making process: Conceptual framework and empirical findings.' Energy Policy, 40, 28-38.

Masini, A. \& Menichetti, E. 2013. 'Investment decisions in the renewable energy sector: An analysis of non-financial drivers.' Technological Forecasting and Social Change, 80:3, 510-24.

Menanteau, P., Finon, D. \& Lamy, M.-L. 2003. 'Prices versus quantities: choosing policies for promoting the development of renewable energy.' Energy Policy, 31:8, 799812.

Miles, M. B. 1979. 'Qualitative Data as an Attractive Nuisance: The Problem of Analysis.' Administrative Science Quarterly, 24:4, 590-601.

Miles, M. B. \& Huberman, A. M. 1994. Qualitative data analysis: An expanded sourcebook. Sage.

Miller, C. A. 2000. 'The dynamics of framing environmental values and policy: four models of societal processes.' Environmental values, 211-33.

Munir, K. A. 2002. 'Being Different: How Normative and Cognitive Aspects of Institutional Environments Influence Technology Transfer.' Human Relations, 55:12, 1403-28.

Muñoz, J. I., Sánchez de la Nieta, A. A., Contreras, J. \& Bernal-Agustín, J. L. 2009. 'Optimal investment portfolio in renewable energy: The Spanish case.' Energy Policy, $37: 12,5273-84$. 
Neuhoff, K., Ehrenmann, A., Butler, L., Cust, J., Hoexter, H., Keats, K., Kreczko, A. \& Sinden, G. 2008. 'Space and time: Wind in an investment planning model.' Energy Economics, 30:4, 1990-2008.

Nord, W. R. \& Tucker, S. 1987. Implementing routine and radical innovations. Lexington Books Lexington, MA.

Oliver, C. 1991. 'Strategic Responses to Institutional Processes.' The Academy of Management Review, 16:1, 145-79.

Oliver, C. 1997. 'Sustainable Competitive Advantage: Combining Institutional and Resource-Based Views.' Strategic Management Journal, 18:9, 697-713.

Palm, J. \& Tengvard, M. 2011. 'Motives for and barriers to household adoption of smallscale production of electricity: examples from Sweden.' Sustainability: Science, Practice, \& Policy, 7:1, 6-15.

Patton, M. Q. 1990. Qualitative evaluation and research methods. SAGE Publications, inc.

Peredo, A. M. \& McLean, M. 2006. 'Social entrepreneurship: A critical review of the concept.' Journal of World Business, 41:1, 56-65.

Pettersson, F. \& Söderholm, P. 2009. 'The diffusion of renewable electricity in the presence of climate policy and technology learning: The case of Sweden.' Renewable and Sustainable Energy Reviews, 13:8, 2031-40.

Rip, A. \& Kemp, R. 1998. Technological Change. In: Rayner S., Malone EL (editors). Battelle Press.

Rogers, E. M. 1962. Diffusion of Innovations. New York: The Free Press.

Schoonhoven, C. B., Eisenhardt, K. M. \& Lyman, K. 1990. 'Speeding Products to Market: Waiting Time to First Product Introduction in New Firms.' Administrative Science Quarterly, 35:1, 177-207.

Schumpeter, J. 1934. 'The Theory of Economic Development.' Cambridge, Mass.: Harvard University Press.

Scott, W. R. 1995. Institutions and Organizations. Thousand Oaks: Sage Publications.

Selznick, P. 1996. 'Institutionalism "Old" and "New".' Administrative Science Quarterly, 41:2, 270-77.

Shane, S. 2003. A General Theory of Entrepreneurship. The Individual-Opportunity Nexus. Cheltenham: Edward Elgar.

Shane, S. \& Venkataraman, S. 2000. 'The Promise of Entrepreneurship as a Field of Research.' The Academy of Management Review, 25:1, 217-26.

Sharma, S. 2000. 'Managerial Interpretations and Organizational Context as Predictors of Corporate Choice of Environmental Strategy.' The Academy of Management Journal, 43:4, 681-97.

Shook, C. L., Priem, R. L. \& McGee, J. E. 2003. 'Venture Creation and the Enterprising Individual: A Review and Synthesis.' Journal of Management, 29:3, 379-99.

Sigrist, B. 1999. 'Entrepreneurial opportunity recognition.' Paper presented at A presentation at the Annual UIC/AMA symposium at Marketing/Entrepreneurship Interface, Sofia-Antipolis, France.

Söderholm, P., Ek, K. \& Pettersson, M. 2007. 'Wind power development in Sweden: Global policies and local obstacles.' Renewable and Sustainable Energy Reviews, $11: 3,365-400$.

Söderholm, P. \& Klaassen, G. 2007. 'Wind Power in Europe: A Simultaneous InnovationDiffusion Model.' Environmental and Resource Economics, 36:2, 163-90.

Stavins, R. N. 2003. 'Chapter 9 Experience with market-based environmental policy instruments.' In M. Karl-Göran \& R. V. Jeffrey (Eds.) Handbook of Environmental Economics: 355-435. Elsevier. 
Sutherland, L.-A. \& Holstead, K. L. 2014. 'Future-proofing the farm: On-farm wind turbine development in farm business decision-making.' Land Use Policy, 36, 10212.

Tate, G., Mbzibain, A. \& Ali, S. 2012. 'A comparison of the drivers influencing farmers' adoption of enterprises associated with renewable energy.' Energy Policy, 49:0, 400-09.

Toke, D. 2005a. 'Community wind power in Europe and in the UK.' Wind Engineering, 29:3, 301-08.

Toke, D. 2005b. 'Explaining wind power planning outcomes:: some findings from a study in England and Wales.' Energy Policy, 33:12, 1527-39.

Ucbasaran, D., Westhead, P. \& Wright, M. 2009. 'The extent and nature of opportunity identification by experienced entrepreneurs.' Journal of Business Venturing, 24:2, 99-115.

Ueda, Y., Kurokawa, K., Kitamura, K., Yokota, M., Akanuma, K. \& Sugihara, H. 2009. 'Performance analysis of various system configurations on grid-connected residential PV systems.' Solar Energy Materials and Solar Cells, 93:6-7, 945-49.

Van Manen, M. 1977. 'Linking ways of knowing with ways of being practical.' Curriculum inquiry, 6:3, 205-28.

Voss, C. A. 1985. 'The need for a field of study of implementation of innovations.' Journal of Product Innovation Management, 2:4, 266-71.

Voss, C. A. 1988. 'Implementation: A key issue in manufacturing technology: The need for a field of study.' Research policy, 17:2, 55-63.

Weick, K. E. 2007. 'The generative properties of richness.' Academy of management journal, 50:1, 14-19.

Wittneben, B. B. F. 2012. 'The impact of the Fukushima nuclear accident on European energy policy.' Environmental Science \& Policy, 15:1, 1-3.

Wüstenhagen, R. \& Menichetti, E. 2012. 'Strategic choices for renewable energy investment: Conceptual framework and opportunities for further research.' Energy Policy, 40, 1-10.

Yin, R. K. 1984. Case study research: Design and methods. Washington DC: Cosmo corp.

Zahra, S. A., Gedajlovic, E., Neubaum, D. 0. \& Shulman, J. M. 2009. 'A typology of social entrepreneurs: Motives, search processes and ethical challenges.' Journal of Business Venturing, 24:5, 519-32.

Zimmerman, M. A. \& Zeitz, G. J. f. 2002. 'Beyound survival: Achieving new venture growth by building legitimacy.' Academy of management review, 27:3, 414-31.

Zucker, L. G. 1987. 'Institutional Theories of Organization.' Annual Review of Sociology, 13, 443-64. 


\section{Part II}

\section{Papers}

The articles associated with this thesis have been removed for copyright reasons. For more details about these see:

http://urn.kb.se/resolve?urn=urn:nbn:se:liu:diva-103319 